\title{
LOS DERECHOS DE LOS ARTISTAS, DE LOS MUSEOS Y DEL PÚBLICO: NECESIDAD DE ARMONIZACIÓN
}

\author{
GUSTAVO JUAN SCHÖTZ*
}

\section{RESUMEN}

Los museos han ampliado su tradicional actividad, que ahora no se limita al ámbito físico de sus instalaciones. La digitalización de las colecciones, junto con el uso de medios audiovisuales y multimediales, no siempre tiene cabida en las normas nacionales e internacionales del derecho de autor. El público, por su parte, mediante el uso generalizado de dispositivos electrónicos y las redes sociales, expande el alcance de los museos y la disponibilidad de reproducciones de las obras. El trabajo analiza distintas situaciones que involucran los derechos morales y patrimoniales de los artistas en la actividad museística. Se recogen algunas soluciones de la legislación comparada y se proponen otras basadas en los principios de la disciplina del derecho de autor, bajo el prisma de la armonización de derechos. También se hace referencia a las negociaciones internacionales que tienen lugar en la OMPI para armonizar estos derechos frente a los desafíos que plantean los usos transfronterizos de las reproducciones.

Palabras clave: museos; derechos de autor; obras plásticas; excepciones y limitaciones; derechos morales; derechos patrimoniales; buenas prácticas; contratos.

\footnotetext{
* Abogado por la Universidad de Buenos Aires y doctor en Derecho por la Universidad Austral. Profesor de la Maestría en Propiedad Intelectual de la Universidad Austral. Ex director nacional del Derecho de Autor, República Argentina (2015-2019). Consultor independiente en Schötz \& Viascán. Buenos Aires (Argentina). Contacto: gschotz@ius.austral.edu.ar. Fecha de recepción: 20 de febrero de 2020. Fecha de aceptación: 28 de marzo de 2020. Para citar el artículo: schötz, Gustavo juAn. Los derechos de los artistas, de los museos y del público: necesidad de armonización. Revista La Propiedad Inmaterial n. ${ }^{\circ}$ 29, Universidad Externado de Colombia, enero-junio, 2020, pp. 137-181. DoI: https://doi.org/10.18601/16571959.n29.06.
} 


\section{THE RIGHTS OF ARTISTS, MUSEUMS AND THE PUBLIC:}

NEED FOR HARMONIZATION

\section{ABSTRACT}

Museums have expanded their traditional activity, which is now not limited to their physical facilities. The digitization of collections, together with the use of audiovisual and multimedia resources, does not always have a full consideration in national and international copyright standards. The public, on the other hand, through the widespread use of electronic devices and social networks, expands the scope of museums and the availability of the reproductions of the works. This paper analyses different situations that involve the moral rights and the copyright of the artist in museums activity. Some solutions to the comparative legislation are explained and others are proposed based on the principles of copyright discipline, under the theory that while interests may be opposed, rights must be harmonized. There was also reference to the international negotiations that took place in WIPO to harmonize these rights facing the challenges posed by cross-border uses of the reproductions of the works.

Keywords: museums; author rights; artistic works; limitations and exceptions; moral rights; economic rights; best practices; contracts.

\section{INTRODUCCIÓN ${ }^{1}$}

Desde hace tiempo el derecho de autor recibe cuestionamientos de quienes lo ven como un obstáculo para el acceso a la cultura o para la vigencia de derechos fundamentales como la libertad de expresión o la educación. Uno de esos ámbitos es el de los museos. Dos son los factores que han llevado a incrementar las dificultades. El primero surge del cambio tecnológico, ya que los museos han pasado de la exhibición pasiva a un rol más proactivo en el ámbito educativo, comunicacional y de difusión de la cultura. Su presencia no se limita al ámbito de sus instalaciones y a las salas de exhibición, recibiendo a los visitantes, sino que procuran la atención del público de diversos modos, incluyendo las visitas virtuales, la creación de obras multimedia o audiovisuales, las muestras itinerantes, la organización de actividades culturales, el mercadeo, entre otras. Muchas de estas iniciativas son parte de la cotidianidad de los museos, que cumplen un papel más ambicioso que aquel que les dio origen ${ }^{2}$. Esas iniciativas generan inconvenientes al momento de

1 Agradezco los comentarios y la colaboración recibidos de Claudia Viascán, Fabrizio Módica, Juan José Marín López, Brenda Puleston y Hugo Rivas Gálvez.

2 Cfr. Lima, María Clara, Guía de Buenas Prácticas - Administración de la Propiedad Intelectual en museos y archivos de la Argentina, Edulp, La Plata, 2011, p. 22. 
cumplir con la legislación autoral, como, por ejemplo, la resignificación de las obras mediante la participación interactiva con el público ${ }^{3}$.

El segundo factor es la incidencia omnicomprensiva de internet, que permite acceder a reproducciones de las piezas y los contenidos del museo desde plataformas y dispositivos personales ${ }^{4}$. Esto excede al tradicional derecho de exhibición, que resulta connatural a la propiedad del soporte físico de las obras. Esas nuevas formas de disponer de las piezas no suelen tener un correlato en la legislación autoral. Tampoco son parte de los contratos que determinan la incorporación de una obra al acervo del museo, ya sea en propiedad, depósito o préstamo. Por otra parte, las reglamentaciones y buenas prácticas de la actividad museística no siempre pueden resolver todas las posibles situaciones. Como telón de fondo, ante la falta de previsiones específicas en la legislación, siempre se aplicarán dos de los principios más relevantes del derecho de autor: el de especialidad o independencia de los derechos y el in dubio pro auctoris ${ }^{5}$.

También se deben considerar los derechos del público en general. La actividad de los museos está destinada a difundir la cultura, a provocar la admiración y el disfrute por la belleza, a educar el intelecto, a incentivar la capacidad creativa mediante la mímesis, a engrandecer a los artistas a través del reconocimiento de su talento. Los destinatarios de esa actividad en muchos casos llevan adelante actos de reproducción de las obras exhibidas, mayormente privados, pero que hoy día son la base de actos de comunicación al público o puesta a disposición en las redes sociales. Por tanto, también será necesario determinar la validez de esos actos.

De aquí que la misión y actividades de los museos y los intereses de los artistas en relación con el derecho de autor sea un ámbito que requiere armonización de derechos ${ }^{6}$. Expondré algunas de las dificultades que se han presentado y propondré algunas de las posibles soluciones, tanto en el ámbito interno como en el internacional. Al expandirse la actuación de los museos gracias a las nuevas posibilidades tecnológicas, los límites de la sala de exhibición se tornan difusos.

3 Cfr. Carpenter, Megan M., "Drawing a Line in the Sand: Copyright Law and New Museums”, 13 Vand. J. Ent. \& Tech. L. 463 (2011), disponible en https://scholarship.law.tamu. edu/facscholar/327 última visualización 27 de enero de 2020.

4 A modo de ejemplo, los 14 museos de la Villa de París comparten una plataforma en la que 321.078 obras están en línea, de las cuales aproximadamente la mitad son de libre acceso. http://parismuseescollections.paris.fr/fr, última visualización 27 de enero de 2020. Cuando el museo tiene libre disponibilidad, las imágenes están sujetas a las condiciones de una licencia Creative Commons. Cuando no tiene disponibilidad, las imágenes están bajo "derechos reservados", con licencia de https://www.adagp.fr/, debiendo revisarse las condiciones de cada una de las imágenes o videos. Cfr. http://parismuseescollections.paris.fr/fr/conditions-generales-d-utilisation, última visualización 27 de enero de 2020 .

5 Cfr. Lipszyc, Delia y colaboradores, Régimen Legal de la Propiedad Intelectual, Hammurabi, Buenos Aires, 2019, p. 75 y ss. Cfr. también Emery, Miguel Ángel, Propiedad Intelectual, 2a edición actualizada y ampliada, Astrea, Buenos Aires, 2019, p. 94 y ss.

6 Esta trilogía de intereses y los eventuales conflictos ya fueron puestos de resalto hace por lo menos 25 años, cuando todavía no había explotado el fenómeno de internet y la digitalización. Cfr. Rivero Hernández, Francisco, "Reproducción de la obra plástica propiedad de museos y colecciones privadas", Revista Critica de Derecho Inmobiliario, n. ${ }^{\circ}$ 622, mayo-junio 1994, pp. 1149-1198. 
Con la digitalización de las colecciones, la incorporación a audiovisuales o la adaptación mediante el uso de la holografía se evita el traslado físico para disfrutar de las obras, aunque la experiencia sea menos enriquecedora ${ }^{7}$. Los nuevos modos no suelen tener cabida en el marco legal existente, ya que no se puede presumir la cesión de los derechos al museo, aunque este hubiera adquirido la obra, debido a que solo tiene en propiedad el soporte, acorde con la tradicional distinción entre corpus mystichum y corpus mechanichum.

En primer lugar, expondré el marco teórico de la armonización de derechos, ya que, entiendo, es el camino para lograr satisfacer los intereses legítimos de las partes involucradas. Luego mostraré los principales conflictos que se suelen presentar entre museos, artistas y público, y propondré soluciones para algunos de ellos. Finalmente, haré un breve resumen del estado de la cuestión en las negociaciones internacionales que se llevan adelante en el seno de Comité de Derechos de Autor y Derechos Conexos de la Organización Mundial de la Propiedad Intelectual (OMPI) (sCCR, por su sigla en inglés).

\section{LA ARMONIZACIÓN DE DERECHOS \\ EN EL ÁMBITO DEL DERECHO DE AUTOR}

\section{A. PROPIEDAD INTELECTUAL Y OTROS DERECHOS FUNDAMENTALES}

Es habitual que se presente a la propiedad intelectual en general y al derecho de autor en particular como un obstáculo para alcanzar bienes humanos superiores ${ }^{8}$. Los debates se dan respecto del derecho a la salud y las dificultades que plantean las patentes al incrementar el precio de los medicamentos ${ }^{9}$. También entre el derecho a la alimentación y la propiedad intelectual en plantas. Distintos organismos de Naciones Unidas abordaron el asunto. En lo que se refiere al derecho de autor y al acceso a la cultura, los documentos más relevantes fueron emitidos por el Comité

\footnotetext{
7 De acuerdo con Brenda Puleston, "Los recorridos virtuales no generan una experiencia transformadora ya que no se produce una experiencia estética, sino que empodera la figura de los Museos como propietarios de esas colecciones" (entrevista con la artista).

8 Entre la literatura más conocida al respecto, aunque no necesariamente referida de modo expreso al derecho de autor, vale la pena mencionar: Grosheide, Willem, Intellectual Property and Human Rights. A Paradox, Cier-Edward Elgar Publishing Limited, Cheltenham, 2010; Torremans, Paul L. C. (ed.), Intellectual Property and Human Rights, 2nd Edition, Kluwer Law International, The Netherlands, 2008; Grosseries, Axel, Marciano, Alain y Strowel, Alain (editores), Intellectual Property and Theories of Justice, Ed. Palgrave Macmillan, Londres, 2010; Cornides, Jakob, "Human Rights and Intellectual Property - Conflict or Convergence?”, Journal of World Intellectual Property (2004), pp. 131-167; Сотtier, T., Bürgi, E. y Paumelyn, J. (eds.), Human Rights in International Trade, Oxford University Press, Nueva York, 2005. Yu, Peter K., "Ten Common Questions About Intellectual Property Rights and Human Rights", Georgia State University Law Review, vol. 23-4, pp. 709-753.

9 Ya abordé la armonización de derechos en el ámbito de la propiedad intelectual y la salud junto con otros colegas en Schötz, Gustavo (coord.), Patentes y Medicinas Esenciales, Heliasta-Universidad Austral, Buenos Aires, 2013.
} 
de Derechos Económicos, Sociales y Culturales, en las declaraciones 17 del 12 de enero de 2006 y 21 del 17 de mayo de $2010^{10}$.

En derecho de autor, las voces se alzan contra el ejercicio de los derechos exclusivos de los titulares frente al acceso a los textos educativos o el uso de una obra para ilustrar una parodia ${ }^{11}$. Los reclamos de remuneración que hace la prensa por el uso no autorizado de sus contenidos son presentados como una limitación al derecho a informar y ser informado ${ }^{12}$. Estos planteos fueron recurrentes durante el reciente debate que se produjo en Europa con ocasión de la discusión sobre la Directiva (UE) 2019/790 del Parlamento Europeo y del Consejo del 17 de abril de 2019 sobre los derechos de autor y derechos afines en el mercado único digital y por la que se modifican las directivas 96/9/CE y 2001/29/CE. En los países de la región también es un debate abierto ${ }^{13}$.

Sin embargo, entiendo que es posible superar una visión binaria del problema en términos de "derechos exclusivos" vs. "limitaciones y excepciones" y lograr un equilibrio ${ }^{14}$. Al respecto, los sistemas jurídicos tienen distintos mecanismos para lograr compatibilizar intereses contrapuestos. Entre las teorías jurídicas predominantes, me inclino por la armonización de derechos, con el fin de evitar la dicotomía de "derechos príncipe" y "derechos cenicienta"15. La doctrina de la armonización postula que los derechos deben ser interpretados de tal modo que no se excluyan

10 Documentos E/C.12/GC/17 y E/C.12/GC/21/Rev.1, respectivamente. A modo introductorio del estado de la cuestión en Naciones Unidas, cfr. Chapman, Audrey R. "Approaching intellectual property as a human right: obligations related to Article 15 (1) (c)", Unesco Copyright Bulletin, volume xxxv, n. ${ }^{\circ}$ 3, July-September 2001, pp. 4-36.

11 Cfr. Dessemontet, Francois, "Copyright and Human Rights", en Intellectual Property and Information Law, Jan Kabel (ed.), Kluwer, 1998, p. 113. También Fischman Afori, Orit, "Human Rights and Copyright: The Introduction of Natural Law Considerations into American Copyright Law”, 14 Fordham Intell. Prop. Media \& Ent. L.J. 497 (2004), pp. 508 y ss. Disponible en https://ir.lawnet.fordham.edu/iplj/vol14/iss2/4.

12 Cfr. Malovic, Nedim, "Swedish Supreme Court favours copyright protection over freedom of information and of the press", IPKat, 22 de marzo de 2020, disponible en http://ipkitten.blogspot.com/2020/03/swedish-supreme-court-favours-copyright.html. También GEIGER, Christophe y Izyumenko, Elena, "Freedom of expression as an external limitation to copyright law in the EU: The Advocate General of the CJEU shows the way", Center for International Intellectual Property Studies, Research Paper n.o 2018-12. van Deursen, Stijn y Snijders, Thom, "The Court of Justice at the Crossroads: Clarifying the Role for Fundamental Rights in the EU Copyright Framework, IIC (2018) 49:1080-1098.

13 Es frecuente que en el debate político se propongan cambios normativos, incluyendo la previsión de nuevas limitaciones y excepciones. Entre otros, cfr. Marzetti, Maximiliano, Propuestas para ampliar el acceso a los Bienes Públicos en Argentina, Clacso, Buenos Aires, 2013, p. 55 y ss. Busaniche, Beatriz, Propiedad intelectual y derechos humanos. Hacia un sistema de derecho de autor que promueva los bienes culturales, Tren en Movimiento, Temperley, 2016, p. 95.

14 Respecto a esta visión binaria "derechos exclusivos" vs. "limitaciones y excepciones", cfr. Gervais, Daniel, "The Internet Taxi: Collective Management of Copyright and the Making Available Right, after the Pentalogy", en The Copyright Pentalogy, Michael Geist (dir.), University of Ottawa Press, Ottawa, 2013, pp. 373-401.

15 Cfr. Serna, Pedro y Toller, Fernando, La Interpretación Constitucional de los Derechos Fundamentales. Una Alternativa a los Conflictos de Derechos, La Ley, Buenos Aires, 2000. Las otras teorías son el balancing test o ponderación y la jerarquización de derechos. La teoría de la armonización es compatible con la aplicación del principio de proporcionalidad y con el de razonabilidad, este último frecuentemente aplicado por la Corte Suprema de Justicia de la República Argentina y otros tribunales, como el TJUE. 
mutuamente, ya que no están enfrentados en un juego de suma cero ni en una jerarquización que signifique excluir alguno de ellos privilegiando otros ${ }^{16}$. Los derechos de propiedad intelectual tienen en común con los demás derechos la búsqueda del bienestar de las personas y sus comunidades. Se debe presumir que cuando se establece un derecho o conjunto de ellos, se hace en función de políticas públicas que propenden al bien común.

Debido a que el derecho de autor está incluido en el catálogo de derechos humanos, es necesario encontrar un mecanismo para que pueda coexistir con los otros derechos de igual jerarquía ${ }^{17}$. Así lo ordena el artículo 29 de la Convención Interamericana de Derechos Humanos:

Artículo 29. Normas de interpretación. Ninguna disposición de la presente Convención puede ser interpretada en el sentido de:

(a) permitir a alguno de los estados partes, grupo o persona, suprimir el goce y ejercicio de los derechos y libertades reconocidos en la Convención o limitarlos en mayor medida que la prevista en ella;

(b) limitar el goce y ejercicio de cualquier derecho o libertad que pueda estar reconocido de acuerdo con las leyes de cualquiera de los estados partes o de acuerdo con otra convención en que sea parte uno de dichos estados;

(c) excluir otros derechos y garantías que son inherentes al ser humano o que se derivan de la forma democrática representativa de gobierno, y

(d) excluir o limitar el efecto que puedan producir la Declaración Americana de Derechos y Deberes del Hombre y otros actos internacionales de la misma naturaleza ${ }^{18}$.

El primer paso para la búsqueda de una solución es la identificación del conflicto. Se trata de verificar y describir intereses contrapuestos cuyo desarrollo individual produce una colisión ${ }^{19}$. Luego, se debe reafirmar que los derechos deben ser interpretados armónicamente, de modo que unos no excluyan a otros. Cada derecho tiene

16 Cfr. Toller, Fernando, "Resolución de los conflictos entre derechos fundamentales, una metodología de interpretación constitucional alternativa a la jerarquización y el balancing test”, en Interpretación Constitucional, Eduardo Ferrer Mac-Gregor (coord.), Editorial Porrúa, México, 2005, t. II, pp. 1199-1284.

17 Cfr. Córdoba Marentes, Juan Fernando, El derecho de autor y sus límites, Editorial Temis, Bogotá, 2015, pp. 59-69. Por un desarrollo en profundidad de la aplicación del principio de proporcionalidad a los derechos humanos y el derecho de autor, cfr. De la Parra Trujillo, Eduardo, Derechos humanos y derechos de autor. Restricciones al derecho de explotación, 2. ${ }^{\mathrm{a}}$ ed., Instituto de Investigaciones Jurídicas, Serie Estudios Jurídicos n. ${ }^{\circ}$ 721, unAm, CDMx, 2015.

18 Convención Americana sobre Derechos Humanos (Pacto de San José), firmada el 22 de noviembre de 1969. Publicada en la Gaceta Oficial n.o 9460 del 11 de febrero de1978.

19 Cfr. Lorenzetti, Ricardo L., "El juez y las sentencias difíciles - Colisión de derechos, principios y valores", LL 1998-A, 1039-1054, en 1044. 
sus propios límites internos, consistentes en la razón por la cual fueron establecidos en cuanto derechos ${ }^{20}$. También hay que recordar que los derechos reconocidos en los tratados de derechos humanos y los incluidos en las declaraciones de derechos de las constituciones de los países son complementarios, por tanto, todos ellos deben ser satisfechos ${ }^{21}$. Las soluciones prácticas de la coexistencia no se resuelven al modo de una fórmula matemática ${ }^{22}$.

\section{B. DETERMINAR LAS SITUACIONES QUE}

\section{REQUIEREN EXCEPCIONES O LIMITACIONES}

Las situaciones que se plantean entre los museos, los artistas y el público no siempre tienen solución en el marco normativo actual, ya sea de un país o de la comunidad global. Son circunstancias que no fueron previstas al momento de diseñar las normas; por tanto, la tarea inicial será ver si esos hechos encajan en la descripción fáctica que comprende toda norma. Luego, habrá que analizar si es posible aplicar la analogía y otros métodos interpretativos. Finalmente, se deberá ver si los principios generales del sistema nos brindan una posible solución para ese caso particular. Si todo lo anterior resulta insatisfactorio y si los casos particulares se tornan en generales, recién ahí será necesario establecer una nueva regla que contemple la situación no prevista.

Cabe aquí hacer lugar a la distinción entre principios y reglas en el entramado de normas que forman el sustrato de la protección autoral, así como de los derechos y pretensiones de los museos y del público en el acceso a las obras. Las diferencias fundamentales entre reglas y principios están dadas por su fuerza deóntica y por su distinta virtualidad al momento de aplicarse. En cuanto al primer aspecto -la fuerza deóntica-, lo que la regla ordena no admite distintos niveles de cumplimiento: es determinativa. Por su parte, los principios deben ser observados en la mayor medida posible, de modo que se optimice su aplicación ${ }^{23}$. Los principios, considerados como mandatos de optimización que requieren ponderación, son necesarios para desarrollar el sistema jurídico, y especialmente para la elaboración de las reglas, tanto generales como particulares, incluyendo las decisiones judiciales ${ }^{24}$. No debemos olvidar que los principios no pretenden ser exclusivos y en muchos casos coexisten con otros al momento de establecer una misma consecuencia jurídica,

20 Respecto de los límites internos de los derechos o su contenido esencial, cfr. Serna y TOLler, La interpretación constitucional de los derechos fundamentales, p. 43 y ss.

21 Lorenzetti, "El juez y las sentencias difíciles...", p. 1045, con cita de jurisprudencia de la Corte Suprema de Justicia de la Nación, República Argentina, Fallos: 236:103; 181:343; 259:403.

22 Derclaye, Estelle, "Intellectual Property Rights and Human Rights: Coinciding and Cooperating", en Torremans, Paul L. C. (ed.), Intellectual Property and Human Rights, pp. 133-160, en 137-138.

23 Cfr. Cianciardo, Juan, "Principios y reglas: una aproximación desde los criterios de distinción", Boletín Mexicano de Derecho Comparado, nueva serie, año xxxvı, n. ${ }^{\circ}$ 108, septiembre-diciembre de 2003, p. 895.

24 De la Parra Trujillo, Derechos humanos y derechos de autor, p. 72. 
debido a que protegen ciertos bienes fundamentales de las personas, sin establecer concretos cursos de acción ${ }^{25}$. Por su parte, las reglas apuntan a alcanzar bienes que son extrínsecos a ellas y determinan conductas precisas.

Muchas de las garantías constituciones y cláusulas de protección de los derechos humanos están estructuradas como principios ${ }^{26}$. Entre estas, los dos elementos que conforman el artículo 27 de la Declaración Universal de Derechos Humanos y que se refieren al derecho de los autores y el de acceso a la cultura ${ }^{27}$. El artículo 9.2 del Convenio de Berna, conocido como "regla de los tres pasos", también está expresado en forma de principio, no de regla, de allí que cada limitación y excepción deba establecerse por ley ${ }^{28}$. Otro tanto se puede decir del artículo 75 inciso 19 de la Constitución Nacional de la República Argentina, que en un solo párrafo propone objetivos de política pública que requieren concreción: "Corresponde al Congreso: [...] Dictar leyes que protejan la identidad y pluralidad cultural, la libre creación y circulación de las obras del autor; el patrimonio artístico y los espacios culturales y audiovisuales".

Para contar con una regla clara que establezca un derecho exigible se debe determinar el supuesto derecho y la consecuencia jurídica: qué se puede o qué no se puede hacer y qué consecuencias hay en hacer o no hacer aquello que está prohibido o permitido ${ }^{29}$. En particular, quiénes son los sujetos beneficiarios, respecto de qué actos, en qué situaciones y para qué fines sería lícita la reproducción, comunicación al público, puesta a disposición, ya sea sin solicitar autorización o bien remunerando, en qué casos especiales no se atentará contra la explotación normal de la obra, lo cual depende del tipo de obra y cuál es su modo de disfrute. Las limitaciones y excepciones se deben diseñar para situaciones específicas, al menos en los sistemas jurídicos continentales de derecho de civil.

25 Canaris, Claus-Wilhelm, El Sistema en la Jurisprudencia, Fundación Cultural del Notariado, Madrid, 1998, trad. de la 2a ed. alemana de Juan Antonio García Amado (Systemdenken und Systembegriff in den Jurisprudenz: entwickelt am Beispiel des deutschen Privatrechts. 2. Überarbeitete Auflage. Berlin, 1983), p. 62.

26 De la Parra Trujillo, Derechos humanos y derechos de autor, p. 49.

27 Declaración Universal de los Derechos Humanos, adoptada y proclamada por la Asamblea General de las Naciones Unidas en su resolución 217 A (III), de 10 de diciembre de 1948. "Artículo 27 1. Toda persona tiene derecho a tomar parte libremente en la vida cultural de la comunidad, a gozar de las artes y a participar en el progreso científico y en los beneficios que de él resulten. 2. Toda persona tiene derecho a la protección de los intereses morales y materiales que le correspondan por razón de las producciones científicas, literarias o artísticas de que sea autora”.

28 Cfr. Córdoba Marentes, El derecho de autor y sus límites, p. 208. Convenio de Berna para la Protección de las Obras Literarias y Artísticas, artículo 9.2: "Se reserva a las legislaciones de los países de la Unión la facultad de permitir la reproducción de dichas obras en determinados casos especiales, con tal que esa reproducción no atente a la explotación normal de la obra ni cause un perjuicio injustificado a los intereses legítimos del autor".

29 Cfr. Schuster, Santiago, Las excepciones al derecho de autor como normas permisivas. Una revisión crítica del derecho de usuario en el sistema normativo de derecho de autor, Universidad de Chile, tesis para optar al Grado de Doctor en Derecho, noviembre de 2019, manuscrito inédito, p. 110 y ss. El autor realiza un análisis novedoso de las limitaciones y excepciones como normas permisivas, acudiendo a herramientas de la analítica del derecho, siguiendo a Hohfeld, Von Wright, Alchourron y Bulygin, entre otros. 
Así, cuando una persona se fotografía junto a una escultura instalada en una plaza pública, estaríamos ante un uso normal y previsto para ese tipo de obra. El transeúnte que se retrata junto a la obra de arte no comete una infracción y por tanto no hace falta tener una excepción específica. Esa conducta cae bajo la gran garantía constitucional (principio) que indica que "Las acciones privadas de los hombres que de ningún modo ofendan al orden y a la moral pública, ni perjudiquen a un tercero, están sólo reservadas a Dios, y exentas de la autoridad de los magistrados" (art. 19 Constitución Nacional de la República Argentina). Pero si se trata de la edición y distribución de libros con fotografías de esa y otras esculturas, lo más probable es que exceda la finalidad para la cual el escultor la colocó allí, incluso considerando el contrato que celebró con el municipio para su elaboración e instalación. Ese uso secundario, no previsto y que puede significar un beneficio económico para un tercero y del que el artista no participa, causaría un perjuicio injustificado a sus derechos de autor, ya que podría haber negociado un precio mayor por su encargo en previsión de los ingresos extraordinarios. Este ejemplo ha dado lugar a excepciones (reglas) en algunos sistemas jurídicos, bajo el nombre de "excepción panorama"

Para que el museo pueda llevar a cabo ciertos usos sin afectar los derechos del artista, en muchos casos se requerirá una norma especial o bien un contrato que prevea esos usos a favor del museo. La reproducción de las obras mediante la fotografía, las réplicas, ya sean bidimensionales o tridimensionales, el mercadeo, serían usos no autorizados. Lo mismo si la obra plástica es incorporada a una obra audiovisual ${ }^{31}$.

Otras veces las soluciones vienen dadas en cuerpos normativos ajenos a la propiedad intelectual, como es el caso de la legislación sobre patrimonio cultural. La intersección entre la propiedad intelectual y el patrimonio cultural puede generar aparentes conflictos ya que atienden a objetivos diversos y no siempre están armonizadas. Mientras que la propiedad intelectual es un sistema de protección e incentivo de la creación, el patrimonio cultural establece las condiciones para que esa creación sea considerada parte de la cultura de un pueblo, convirtiéndola en un bien sujeto al goce colectivo ${ }^{32}$.

30 A modo de ejemplo, el art. 71.F. de la Ley 17.336 de la República de Chile la prevé del siguiente modo: "Asimismo, la reproducción mediante la fotografía, el dibujo o cualquier otro procedimiento, de monumentos, estatuas y, en general, las obras artísticas que adornan permanentemente plazas, avenidas y lugares públicos, es libre y no está sujeta a remuneración, siendo lícita la publicación y venta de las reproducciones".

31 La película Mi obra maestra, de Gastón Duprat, incluye, entre otras obras de arte, la de Carlos Gorriarena a la que el protagonista Renzo Nervi (en la actuación de Luis Brandoni) le dispara con una pistola y daña irremediablemente. En los créditos aparecen todos los artistas plásticos que aportaron sus obras a la obra cinematográfica. Esa situación solo resultó posible por los contratos celebrados con los artistas o sus herederos. Cfr. https://www.imdb. com/title/tt7605922/.

32 Cfr. Anguita Villanueva, Luis Antonio, "La extraña pareja: la difícil relación jurídica entre la normativa de propiedad intelectual y la de patrimonio cultural en los museos", en Museos y Propiedad Intelectual, Carlos Rogel y Andrés Domínguez (directores), Reus, Madrid, 2012, p. 116 . 
A continuación, y a modo de ejemplo, veremos cómo un caso particular muchas veces no puede ser aprehendido de modo perfecto por una regla. De aquí que algunos aspectos encuentran solución acudiendo a los principios del microsistema del derecho de autor, como parte del más amplio de la propiedad intelectual, o bien al más abarcador conformado por el conjunto de los derechos y garantías constitucionales.

\section{UN CASO EMBLEMÁTICO: BANKSY EN MILÁN}

Para ilustrar la situación, es interesante recrear un evento reciente. El 15 de enero de 2019, un tribunal de Milán dictó una sentencia que tuvo por objeto algunas obras del artista Banksy ${ }^{33}$. Este autor es uno de los máximos exponentes del "arte callejero" y profundo crítico del consumismo, el belicismo y la corrupción política. Ha creado y expuesto muchas de sus obras en la vía pública de modo permanente. Algún desprevenido podría creer que Banksy hace abandono de sus derechos de autor al dejar sus obras a la intemperie, a merced del vandalismo y de lo que le plazca hacer al dueño de los muros donde el artista pinta. En el juicio mencionado, Banksy dejó en claro que nunca renunció a ellos. Por el contrario, hace un uso propio, singular y desafiante del derecho de autor, sin que sus obras estén en el dominio público ${ }^{34}$.

He aquí los hechos. En octubre de 2018 se anunció la inauguración de la exposición "El arte de Banksy. Una protesta visual" para el siguiente mes de noviembre, curada por Mercury y producida por 24 Ore Cultura s. R. L., una empresa que organiza muestras y exhibiciones. Se trataba de una muestra retrospectiva que expondría más de setenta obras atribuidas al autor, incluyendo algunas piezas en propiedad de coleccionistas y gigantografías reproduciendo algunos de los murales existentes en diversos lugares del mundo ${ }^{35}$.

Pest Control Office, la fundación demandante en representación de los derechos de Banksy, emite certificados de originalidad de sus obras y es titular de la marca

33 Acorde con Wikipedia, Banksy (Yate, Gloucestershire, Inglaterra, 1974) es el seudónimo de un artista de arte urbano británico. Cfr. https://es.wikipedia.org/wiki/Banksy. La sentencia referida es: "Tribunale di Milano, Sezione xIV, Sezione specializzata in materia di Impresa A, ordenanza nel procedimento cautelare iscritto al N. 52442/2018 R.G. promosso da Pest Control Office Limited ricorrente, contro 24 Ore Cultura s. R. L. resistente, Presidente dott. Claudio Marangoni”, en https://drive.google.com/file/d/1zNsBLCfBCKA1v9yp2FwLb_s-98VSY3Uj/view. $34 \mathrm{El}$ arte callejero presenta frecuentemente casos de difícil solución. Tal vez el más reciente y famoso es el resuelto luego de siete años de disputas en el que se indemnizó con 6,7 millones de dólares a un grupo de grafiteros por la destrucción del inmueble en Long Island en el que plasmaron sus obras, conocido como "5Pointz". Cfr. United States Court of Appeals, Second Circuit n. ${ }^{\circ}$ 18-498, Castillo v. G\&M Realty L.P., February 20, 2020. Disponible en https://cases.justia.com/federal/appellate-courts/ca2/18-498/18-498-2020-02-20.pdf?ts=1582212604.

35 Información extraída de la nota de RosatTi, Eleonora, "Milan court partly sides with Banksy in interim proceedings for trade mark and copyright infringement", IPKat, 2 de marzo de 2019, http://ipkitten.blogspot.com/2019/03/milan-court-sides-with-banksy-in.html, última visualización 27 de enero de 2020. 
"Banksy" y de otros derechos sobre las obras del artista ${ }^{36}$. La fundación solicitó una medida cautelar para impedir la muestra porque además se ofrecía mercadeo con su nombre y marca registrada. La demandante señaló los evidentes riesgos de confusión y la asociación de su nombre y prestigio con productos y publicidades no autorizadas. La medida cautelar fue concedida, predeterminándose un daño de 20 mil euros por cada reproducción que se hiciera de la obra de Banksy sin autorización previa.

Como se puede observar, si bien cualquier persona puede tomar fotografías de la obra exhibida por Banksy en la vía pública, eso no significa que se pueda organizar una muestra con reproducciones ni vender objetos que reproducen las obras. Cada derecho es independiente, la cesión o autorización no se presume y en caso de duda se debe interpretar a favor del autor.

Sin embargo, el tribunal no consideró ilícito el uso del nombre para identificar la exposición dedicada al artista ya que no se configura una infracción al denominar descriptivamente la exhibición de ese particular autor. Tampoco se consideró infracción la inclusión de obras del artista en el catálogo, cuando las obras fueron legítimamente adquiridas por terceros y entregadas temporalmente al expositor. Aquí el tribunal acudió implícitamente al contenido esencial de cada derecho, para establecer sus propios límites internos. Así, la identificación de una muestra utilizando el nombre del artista es un uso informativo legítimo de dicho nombre y no afecta el contenido esencial del derecho marcario de Banksy el que se utilice ese signo para informar respecto de la muestra. No se trata de un uso marcario ni es engañoso para el público, si efectivamente la muestra incluye obras originales del artista. Asimismo, la reproducción de las obras exhibidas en el catálogo, con finalidad informativa, no implica una reproducción no autorizada de la obra, ya que al haber vendido Banksy el ejemplar y autorizar su exhibición, está dentro del derecho del dueño del soporte poder anunciar que la obra será exhibida ${ }^{37}$.

En conclusión, la organización de la muestra no es un ilícito per se, sino que se debe analizar la situación de cada obra y con qué derechos cuenta el museo o los terceros respecto de cada una de ellas. El museo no puede presumir que la posesión o tenencia de un ejemplar signifique autorización para cualquier tipo de acto, en todo momento y para cualquier territorio ${ }^{38}$. Es la aplicación de la tradicional distinción entre corpus mystichum y corpus mechanichum respecto de las obras artísticas ${ }^{39}$.

36 Cfr. http://www.pestcontroloffice.com/ última visualización el 27 de enero de 2020. El curioso nombre es una supuesta alusión al control de la peste de la piratería y el fraude.

37 El derecho del adquirente o legítimo propietario podría presumirse, más aún si el adquirente es el mismo museo. Sin embargo, no parece tan claro que la obra pueda ser exhibida por un tercero que no es propietario del soporte. Cfr. Merryman, John Henry, Elsen, Albert E. y URICE, Stephen K., Law, Ethics and the Visual Arts, fifth edition, Kluwer Law International, The Netherlands, 2007, pp. 528-530.

38 Cfr. Olmedo Velázquez, Efraín, "Limitantes en la adquisición de obras de arte en México", Revista Mexicana del Derecho de Autor, Indautor, n. ${ }^{\circ} 3$, segundo semestre 2013 , ISSN: 2007-5677, México, pp. 84-95. Las consideraciones se refieren al derecho mexicano, pero son equivalentes en todos los países de la región.

39 Romero, Carolina, "Los conceptos corpus mysticum y corpus mechanicum. Su aplicación 
Veamos ahora algunas de las situaciones más usuales que sea plantean como conflictivas en la relación entre los artistas, los museos y el público.

\section{LOS DERECHOS MORALES DE LOS AUTORES}

\section{SOBRE LAS OBRAS EN POSESIÓN DE LOS MUSEOS}

Tratándose de una obra en el dominio privado, es necesario analizar ahora qué derechos tiene sobre ella el museo. Dos son las situaciones: (a) tenencia o posesión de la obra bajo cualquier título, permanente o transitorio, sin contrato de ningún tipo con el titular de los derechos; (b) la misma situación, bajo algún vínculo contractual, reglamento o buena práctica que haya determinado qué derechos tiene el museo sobre las obras.

En el primer caso, hay que aplicar los principios y reglas del sistema nacional e internacional de derecho de autor y las reglas del derecho sobre la propiedad mueble o inmueble. En el segundo, se deberán analizar las condiciones contractuales entre el museo y el titular de los derechos, y con el propietario del soporte. Esto se debe a que las disposiciones especiales para las obras de arte o de ejemplar único no prevén muchas de las posibles situaciones que se pueden presentar ${ }^{40}$. Siempre es conveniente realizar un informe de debida diligencia al momento en que la obra se incorpora al acervo del museo, el que será más relevante si se adquiere o recibe de alguien que no es el mismo autor ${ }^{41}$.

El autor tiene sobre su obra derechos morales y patrimoniales. Los primeros son considerados de modo general por la doctrina y la jurisprudencia irrenunciables, imprescriptibles e inembargables ${ }^{42}$. Esta condición no surge directamente del artículo 6.2 del Convenio de Berna, donde tampoco se ha previsto cómo se ejercerán esos derechos a la muerte del autor ${ }^{43}$. Algunas legislaciones consideran estos caracteres de modo expreso, como el artículo 14 de la Ley española de derecho de autor o el artículo 19 de la Ley Federal de Derecho de Autor de México

hoy en día en el contexto análogo y digital”, Revista Iberoamericana de Derecho de Autor, Unesco-Cerlalc, Año viı - n. ${ }^{\circ} 14$ - enero-diciembre 2014, pp. 156-203.

40 Cfr. Crews, Kenneth D., "Museum Policies and Art Images: Conflicting Objectives and Copyright Overreaching”, Fordham Intell. Prop. Media \& Ent. L. J. Vol. 22:795, p. 802.

41 Cfr. Malaro, Marie C. y DeAngelis, Ildiko Pogáni, A Legal Primer on Managing Museum Collections, Third Edition, Smitshonian Books, Washington, 2012, pp. 176 y 178.

42 Entre la jurisprudencia más representativa, se puede consultar Tribunal Segundo Civil, Sección Segunda Costa Rica, 30 de septiembre de 2002, “Jesús Manuel López Gutiérrez c. Televisora de Costa Rica Sociedad Anónima”, sentencia 00376, disponible en https://aplicaciones. cerlalc.org/derechoenlinea/dar/index.php? mode=archivo\&id=1962, última visualización 27 de enero de 2020. También la profusa jurisprudencia que cita Lipszyc, Régimen Legal de la Propiedad Intelectual, pp. 351 a 362, y la jurisprudencia citada por Emery, Propiedad Intelectual, pp. 341 y 342.

43 Cfr. Antequera Parilli, Ricardo, Estudios de Derecho de Autor y Derechos Afines, AisGeMarcial Pons, Madrid, 2007, p. 80 y ss., donde el autor distingue entre las corrientes monista y dualista respecto del derecho de autor, siendo que la segunda considera que se trata de un derecho personal o de la personalidad. En cuanto al Convenio de Berna de modo específico, cfr. Ricketson, Sam y Ginsburg, Jane, International Copyright and Neighbouring Rights. The Berne Convention and Beyond, Oxford University Press, Nueva York, 2010, Second Edition, vol. I, p. 108 . 
o el artículo L 121-1 del Código de Propiedad Intelectual de Francia ${ }^{44}$. Sobre lo que no quedan dudas es que esos derechos morales no pertenecen al museo ni al propietario del soporte que la entrega al museo en propiedad, comodato o depósito. Son prerrogativas que el artista conserva aún luego de transferida la propiedad de la obra; de aquí que constituyen límites para la actividad museística.

En el caso de legislaciones que no hayan regulado de modo orgánico los derechos morales, al menos el de paternidad e integridad se extienden como mínimo a la vigencia de los derechos patrimoniales, por imperio del Convenio de Berna ${ }^{45}$. Además de estos, aquí consideraremos el de inédito o divulgación y el de retracto o retirada. Debido a que, entendemos, presenta menos dificultades para un museo, no haremos hincapié en el de acceso a la obra ni el de modificación.

Ante colisión entre los derechos morales del autor y los derechos y deberes del museo, hay que considerar que los derechos morales no son una categoría de contenido homogéneo e idéntico para todos los autores, sino adaptada a la naturaleza y al destino de la obra. Adicionalmente, cabe recordar la premisa antes referida, en cuanto a que ninguno de los derechos en aparente conflicto es en teoría y abstractamente superior al otro. En todo caso, ante un supuesto particular, uno de los derechos podrá estar presente en el caso y no el otro. Finalmente, y acorde con el contenido esencial de cada derecho y sus límites internos, ningún derecho puede ejercerse de modo abusivo ${ }^{46}$.

La extensión de los derechos morales y los remedios procesales de su defensa, así como las eventuales disposiciones para su ejercicio post mortem auctoris, son asuntos regulados por la legislación donde se reclama protección (artículo 6 bis 3. del Convenio de Berna). Estamos aquí ante una potencial fuente de conflicto transfronterizo, ya que una conducta lícita en un país podría ser ilícita en otro. Para los museos implica una importante advertencia en relación con sus compromisos con los autores de las obras: el alcance de su obligación de respeto de los derechos

44 Real Decreto Legislativo 1/1996, de 12 de abril, por el que se aprueba el texto refundido de la Ley de Propiedad Intelectual. Art 14: "Corresponden al autor los siguientes derechos irrenunciables e inalienables:”. Por su parte, Ley Federal de Derecho de Autor de México, artículo 19: "El derecho moral se considera unido al autor y es inalienable, imprescriptible, irrenunciable e inembargable". Y el artículo L121-1 del Código de Propiedad Intelectual de Francia indica: "El autor gozará del derecho a que se respete su nombre, su calidad y su obra. Dicho derecho estará vinculado a su persona. Será perpetuo, inalienable e imprescriptible. Éste será transmisible mortis causa a los herederos del autor. Su ejercicio podrá ser conferido a un tercero en virtud de disposición testamentaria”. Traducción disponible en la página de la ompi, https:// www.wipo.int/edocs/lexdocs/laws/es/fr/fr467es.pdf, última visualización del 6 de febrero de 2020 .

45 Convenio de Berna, art. 6 bis 2: "Los derechos reconocidos al autor en virtud del párrafo 1) serán mantenidos después de su muerte, por lo menos hasta la extinción de sus derechos patrimoniales, y ejercidos por las personas o instituciones a las que la legislación nacional del país en que se reclame la protección reconozca derechos. Sin embargo, los países cuya legislación en vigor en el momento de la ratificación de la presente Acta o de la adhesión a la misma, no contenga disposiciones relativas a la protección después de la muerte del autor de todos los derechos reconocidos en virtud del párrafo 1 anterior, tienen la facultad de establecer que alguno o algunos de esos derechos no serán mantenidos después de la muerte del autor".

46 Marín López, Juan José, El conflicto entre el derecho moral del autor plástico y el derecho de propiedad sobre la obra, Aranzadi, Madrid, 2006, pp. 40 y 41. 
morales se limita a los efectos en el territorio nacional donde el museo se encuentra físicamente instalado. Otra cosa sería de difícil cumplimiento por exceder su esfera de actuación, salvo caso de dolo, del que nadie puede exceptuarse.

\section{A. EL DERECHO DE INÉDITO O DE DIVULGACIÓN}

Respecto del derecho de inédito, el museo debe asegurarse de que la obra en su posesión o tenencia haya sido divulgada por el autor o sus herederos. La divulgación debe consistir en un acto voluntario del autor, por el cual quede manifiesto su deseo de dar a conocer la obra al público. Una forma de divulgar la obra es mediante la puesta en el comercio del ejemplar o bien la entrega al comitente si fue una obra por encargo ${ }^{47}$. Si el artista vendió o donó el ejemplar que llega legítimamente a poder del museo, no hay reparos para su exhibición, al menos desde el punto de vista del derecho de inédito. Aquí hay un cierto equilibrio en las relaciones entre autor y propietario, ya que se presume que la venta y entrega del ejemplar es una manifestación de haber querido divulgar la obra.

Pero si el autor no hizo tradición del ejemplar, no se puede presumir su intención de darla a conocer al público. El artista podría argumentar que se trata de una obra inconclusa, o que está en desacuerdo desde un punto de vista estético o ideológico. Si bien se podría insinuar un derecho del público en conocer la obra de un autor o su proceso creativo, el derecho de inédito o de divulgación es primario y básico respecto de los otros derechos, como la exhibición o distribución ${ }^{48}$.

La legislación española previó la situación respecto de aquellas obras que el autor enajenó. En ese caso, el autor no puede oponerse a que su obra se divulgue y exhiba, salvo que la exhibición afecte su honor y reputación ${ }^{49}$. Al considerarse a la exhibición uno de los modos de divulgación de la obra, si la ley asigna ese derecho al propietario del soporte, el autor ya no puede oponerse a dicha divulgación.

47 En contra, Marín López, El conflicto entre el derecho..., p. 117 y ss. Este autor entiende que si bien el propietario tiene el derecho de exposición, será así solo cuando la obra hubiere sido divulgada por el autor. En este sentido, la enajenación del soporte importaría una autorización anticipada para su divulgación. Pero se trataría de una norma dispositiva, que admite una voluntad expresa en contrario. Esta facultad se trasladará a los sucesivos adquirentes por ser propter rem, como sería el caso de un museo que adquiriera la obra con posterioridad.

48 La voluntaria divulgación es un requisito implícito para que se puedan ejercer las excepciones y limitaciones de los artículos 10 y 10 bis del mismo Convenio de Berna. La divulgación es también el paso inicial para que se puedan ejercer los derechos patrimoniales. Cfr. AnTEQUerA Parilli, Estudios de Derecho de Autor y Derechos Afines, p. 83. Ricketson y Ginsburg, International Copyright and Neighbouring Rights, vol. I, n. ${ }^{\circ} 10.37$, p. 614. Marín López, El conflicto entre el derecho moral..., pp. 101 y 102.

49 España, Texto Refundido de la Ley de Propiedad Intelectual, artículo 56: "Transmisión de derechos a los propietarios de ciertos soportes materiales. 1. El adquirente de la propiedad del soporte a que se haya incorporado la obra no tendrá, por este solo título, ningún derecho de explotación sobre esta última. 2. No obstante, el propietario del original de una obra de artes plásticas o de una obra fotográfica tendrá el derecho de exposición pública de la obra, aunque ésta no haya sido divulgada, salvo que el autor hubiera excluido expresamente este derecho en el acto de enajenación del original. En todo caso, el autor podrá oponerse al ejercicio de este derecho, mediante la aplicación, en su caso, de las medidas cautelares previstas en esta Ley, cuando la exposición se realice en condiciones que perjudiquen su honor o reputación profesional”. 
La exhibición en esas condiciones no podría constituir una infracción al derecho de inédito del autor ${ }^{50}$. Sin embargo, algunas exhibiciones particulares podrían afectar el buen nombre y reputación del artista. Por ejemplo, algún tipo de muestra donde esa obra no "encaja" o el contexto resulta inapropiados.

Distinto es el caso del museo que recibe en legado o donación la colección de un autor fallecido y se incluyen obras inéditas. La solución es requerir a los herederos que salven la situación mediante una nota en la que permitan la divulgación de esas obras. Ante la ausencia de herederos o tratarse de obras huérfanas, he aquí un aspecto que debería ser reglamentado por la legislación, ya que resulta frecuente que los museos accedan a obras que permanecen inéditas ${ }^{52}$. Esto también dependerá del tipo de obras. En el caso de las audiovisuales inéditas, ante la falta de productor se debería consultar a los otros titulares.

Algunas legislaciones prevén un beneficio para quien divulga una obra en el dominio público que hasta la fecha hubiera permanecido inédita, otorgándole derechos exclusivos sobre esa obra ajena. Es un balance entre el respeto al derecho del autor de no haber querido divulgar su obra en vida y el derecho de la sociedad a conocer e incrementar su acervo cultural ${ }^{53}$.

\section{B. DERECHO DE PATERNIDAD}

En lo que se refiere al derecho de paternidad, los museos suelen ser muy cuidadosos al indicar los datos de las obras y sus autores. El respeto del derecho al reconocimiento del nombre del creador se extiende también a las reproducciones y otros usos autorizados que realiza el museo, como su página virtual, el catálogo o la publicidad de una muestra o exhibición itinerante. Otro tanto se puede decir respecto de la inclusión de la obra en un audiovisual, caso en el cual debe figurar el nombre del autor en los créditos. Cuando el museo autoriza la reproducción de sus obras para incorporarlas a una publicación de un tercero, deberá trasladar la obligación de mencionar a los autores a dichos terceros ${ }^{54}$. La obligación de mencionar al autor se aplica también a las obras licenciadas bajo Creative Commons, por ser esta una disposición común a todas ellas y debido a que el derecho de paternidad es irrenunciable.

Debe distinguirse el caso de las obras anónimas o bajo seudónimo. En las primeras el autor decidió no figurar, lo cual debe ser respetado. En el caso de las

50 Cfr. Ortega Doménech, Jorge, Obra Plástica y Derechos de Autor, Reus, Madrid, 2000, p. 323 .

51 Ortega Doménech menciona casos jurisprudenciales donde se discutió este aspecto, con resultados dispares. Idem, p. 324.

52 Algunas legislaciones, ante la ausencia de herederos, designan al Estado como representante de los derechos morales. Cfr. Ley Federal de Derecho de Autor de México, artículo 20.

53 Así, Ley de Propiedad Intelectual de España, artículos 129 y 130, estableciendo el período de derechos exclusivos en 25 años desde la divulgación. Cfr. Anguita Villanueva, "La extraña pareja...”, p. 124.

54 Cfr. Crews, "Museum Policies...", p. 818. 
obras seudónimas, el derecho de paternidad se ejerce mencionando siempre el seudónimo por el que el autor desea ser conocido. Ninguna de estas dos situaciones son excepciones al derecho de paternidad sino particulares modos de ejercerlo.

El respeto de este derecho resulta muy importante para el autor cuya obra es exhibida públicamente. Su nombre actúa a modo de marca comercial, siendo fuente de prestigio y reconocimiento, lo cual puede dar lugar a obras por encargo o al aumento de valor de las otras obras de su producción, ya sean existentes o futuras ${ }^{55}$.

No sucede lo mismo con el público visitante, cuando en las redes sociales reproducen o comunican obras sin indicar quién es el autor. En los casos en que resulte lícito captar imágenes de las obras durante las visitas a los museos, aquellas deberían ser compartidas indicando los datos relevantes, como autor, título, fecha y lugar donde están exhibidas ${ }^{56}$. Los museos, como parte de su tarea educativa, deberían indicar a los visitantes que si realizan reproducciones y las hacen disponibles para sus conocidos y amigos, deben al menos indicar quienes son los autores ${ }^{57}$.

El museo no tiene un derecho derivado de la paternidad del autor, ni la ejerce, pero debe respetarla y hacerla respetar. No sucede lo mismo con el derecho del museo a que se mencione el nombre del establecimiento que exhibe la obra. Aquí ya no estamos ante una manifestación del derecho moral del autor, sino de una disposición reglamentaria o contractual que el museo impone a todos aquellos que acceden a la colección, tanto en formato físico-presencial como en el espacio virtual. El museo, como propietario del espacio físico, puede imponer reglas de conducta dentro de sus instalaciones, lo cual le permite ejercitar cierto control sobre su patrimonio, que va más allá del derecho de autor sobre las obras. Una suerte de reglamento de "admisión y permanencia" que establece condiciones para aquellos que acceden a las salas de exhibición ${ }^{58}$.

55 Pantalony, Rina Elster, La gestión de la propiedad intelectual en los museos, ompi, Ginebra, 2013 , p. 20. Además, el museo actúa como legitimador del valor artístico de la obra y determinante de qué es arte y qué no. La exposición en un museo es el momentum del artista, ya que al ser el lugar áurico para apreciar una obra o sentir una experiencia estética, la institución lo legitima (entrevista a la artista Brenda Puleston).

56 La licitud podría estar dada por tratarse de una copia privada para uso personal, en los regímenes que la reglamentan, como el art. 3 de la Decisión 351 de la Comunidad Andina: "Uso personal: Reproducción u otra forma de utilización, de la obra de otra persona, en un solo ejemplar, exclusivamente para el propio uso de un individuo, en casos tales como la investigación y el esparcimiento personal”. Cfr. Guzmán, Diego, Derecho del Arte, Universidad Externado de Colombia, Bogotá, 2018, p. 142.

57 La obligación de indicar el nombre del autor está prevista expresamente en Perú, Ley sobre el Derecho de Autor, Decreto Legislativo n. ${ }^{\circ}$ 822, artículo 43, inciso e: "La reproducción de una obra de arte expuesta permanentemente en las calles, plazas u otros lugares públicos, o de la fachada exterior de los edificios, realizada por medio de un arte diverso al empleado para la elaboración del original, siempre que se indique el nombre del autor si se conociere, el título de la obra si lo tuviere y el lugar donde se encuentra".

58 Ruipérez de AzcÁrate, Clara, "El derecho de autor y sus límites: una encrucijada para los museos", en Museos y Propiedad Intelectual, Carlos Rogel y Andrés Domínguez (directores), Reus, Madrid, 2012, p. 97. También Crews, “Museum Policies...”, p. 806. 


\section{DERECHO DE INTEGRIDAD}

El derecho moral de integridad en las obras de arte adquiere especial relevancia debido a que en las obras de ejemplar único rara vez existen duplicados, como su mismo nombre indica. La integridad del ejemplar adquiere aquí un valor supremo, ya que la personalidad del autor, su creatividad y excelencia están allí representadas. La destrucción o alteración, en caso de ser irreversibles, lo afectan especialmente ${ }^{59}$. No sucede así con las obras que admiten reproducciones; la destrucción de un ejemplar de una obra literaria no afectará el derecho de integridad del autor. También se puede justificar el derecho moral de integridad como un ejercicio de la libertad de expresión del artista, ya que la afectación de su obra sería un acto que cercena su expresión, manifestada a través de la creación artística ${ }^{60}$. Desde este punto de vista, el público y el patrimonio cultural se benefician de la integridad de la obra.

Los museos deben ser precavidos en el respeto al derecho de integridad en las reproducciones autorizadas, ya que las modificaciones a la obra, cualquiera sea el formato, podrían constituir un ilícito. Aún en los casos en que estuviera prevista la libre inclusión de una reproducción en un catálogo para distribuir entre los visitantes, esa reproducción debe ser respetuosa del derecho moral de integridad. Así, hay que evitar reproducir una parte o fracción de la obra en un folleto o catálogo, sin que se muestre la totalidad de esta ${ }^{61}$. Otro tanto se puede decir de retoques o modificaciones por razones editoriales. Lo mismo en los supuestos de reproducciones para mercadeo, cuando el museo estuviera autorizado.

La integridad de la obra no solo afecta a los museos, como queda de manifiesto en la relación de casos jurisprudenciales que efectúa Juan José Marín ${ }^{62}$. Si se tratara de bienes declarados patrimonio histórico, artístico o cultural aparecen deberes adicionales de conservación, a cargo del propietario de la cosa, mueble o inmueble. Un caso especial es el derecho de integridad en relación con la conservación de las obras, en particular de los murales, ya que se presentan problemas derivados de la distinción entre obra y soporte ${ }^{63}$.

59 Cfr. Lee, Brian A., “Making Sense of 'Moral Rights' in Intellectual Property” (February 15, 2012), Temple Law Review, vol. 84, p. 71, 2011; Brooklyn Law School, Legal Studies Paper n. ${ }^{\circ}$ 261, pp. 112 y ss. Disponible en ssRn: https://ssrn.com/abstract=2005753. Cfr. OrTEGA Doménech, Obra Plástica y Derechos de Autor, p. 338 y ss.

60 Treiger-Bar-Am, Leslie Kim, “The Moral Right of Integrity: A Freedom of Expression”, en New Directions in Copyright, vol. 2, Fiona Macmillan (ed.), Edward Elgar, Londres, 2006, p. 136 y ss.

61 La Directiva 2001/29/CE del Parlamento Europeo y del Consejo, del 22 de mayo de 2001 , relativa a la armonización de determinados aspectos de los derechos de autor y derechos afines a los derechos de autor en la sociedad de la información prevé en su artículo 5.3.j: “3. Los Estados miembros podrán establecer excepciones o limitaciones a los derechos a que se refieren los artículos 2 y 3 en los siguientes casos: [...] cuando el uso tenga la finalidad de anunciar la exposición pública o la venta de obras de arte, en la medida en que resulte necesaria para promocionar el acto, con exclusión de cualquier otro uso comercial; [...]". No todos los países de la UE han implementado esta excepción.

62 Marín López, El conflicto entre el derecho moral..., p. 155.

63 Hay abundante jurisprudencia internacional al respecto. Una reseña histórica se encuentra en Merryman et al., Law, Ethics and the Visual Arts, pp. 427-444. El fallo señero de Argen- 
En los museos que contienen murales, se plantea una posible colisión entre el derecho del propietario del inmueble y el derecho del artista. El museo, en ciertas circunstancias, podrá ejercitar su derecho a demoler, reformar o realizar tareas de mantenimiento que afecten la superficie a la que se incorporó la obra. El artista o sus herederos podrían reclamar por el mantenimiento de la obra, en defensa del derecho moral de integridad. ¿Priman los derechos del dueño de la propiedad inmueble, a la que la obra accede, o bien se deben considerar en plenitud los derechos morales imprescriptibles e inalienables? ${ }^{364}$ En una posición extrema, el museo asume un enorme riesgo al incorporar murales u obras tridimensionales, por su agravada obligación de conservación, lo cual haría imposible toda reforma o modificación de las instalaciones o reubicación de las piezas.

El supuesto fue analizado recientemente por la Corte Suprema Federal de Alemania, en tres casos resueltos simultáneamente el 21 de febrero de 2019 (ref.: I ZR 98/17, I ZR 99/17 y I ZR 15/18). Entendió que la destrucción de la obra no siempre significa una afectación ilegítima del derecho moral de integridad ${ }^{65}$. En dos de los tres casos (ref.: I ZR 98/17 y I ZR 99/17), las partes discutieron sobre la admisibilidad de la destrucción de la instalación de las salas multimedia y obras multidimensionales HHole (para Mannheim) 2006 y la instalación ligera PHaradise, ambas creadas en 2006 para la Kunsthalle Mannheim.

La Corte reconoció que la destrucción de una obra es uno de los posibles supuestos de afectación del derecho a la integridad, al menos en la redacción del artículo 14 de la Ley Alemana de Derecho de Autor y Derechos Conexos ${ }^{66}$. Sin

tina en la materia es "Waveluk, María v. Iglesia Ortodoxa”, Cámara Nacional en lo Civil Sala G, 14/10/93, publicado en J.A.1995-II-367. Un fallo más reciente pero igualmente relevante, aunque se discutió más la paternidad que la integridad, es "Seiguerman, Luciano c/Greco, Hernán y Otros s/daños y perjuicios”, de la Cámara Nacional en lo Civil, Sala M, 09/03/2011,

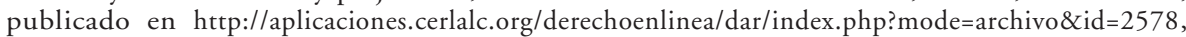
con comentarios de Federico Villalba Díaz. En Colombia es muy relevante la resolución de la Dirección Nacional del Derecho de Autor, en el asunto "Gabriel Antonio Calle Arango v. Centro Comercial Sandiego P. H.”, del 19 de agosto de 2016, con comentario de ToвóN Franco, Natalia, "Limitaciones al derecho moral de obras arquitectónicas", Revista Iberoamericana de la Propiedad Intelectual, Año 2016, tomo IV, p. 248. Esta última resolución fue revocada por la Decisión Civil n. ${ }^{\circ} 6$ del Tribunal Superior del Distrito Judicial de Bogotá de 2 de noviembre de 2017.

$64 \mathrm{El}$ tema es objeto de importantes debates. Cfr. Sánchez Aristi, Rafael, "La propiedad trenzada. El juego de lo material y lo inmaterial en las obras de arte”, en Derecho del Arte, Anuario Iberoamericano 2015, Fundación Prof. Uría, Civitas, Madrid, 2015, pp. 23-109, en 31. Emery, Miguel Ángel, "Los derechos intelectuales de los artistas plásticos. La originalidad en las obras artísticas", Revista El Derecho, Buenos Aires, t. 243 p. 645. Solórzano Solórzano, Raúl, "En torno al derecho moral del autor a la integridad de su obra: reflexiones a propósito del daño efectuado a los murales en el Centro de Lima", Revista de la Facultad de Derecho de la PUCP, Lima, n. ${ }^{\circ}$ 74, 2015, pp. 97-112.

65 Nordemann, Jan Bernd y Leidl, Laura, "German BGH: The destruction of the work does not infringe the moral rights of the author", Kluwer Copyright Blog, 19 de Agosto de 2019, disponible en http://copyrightblog.kluweriplaw.com/2019/08/19/german-bgh-the-destruction-of-thework-does-not-infringe-the-moral-rights-of-the-author/, última visualización 6 de febrero de 2020 .

$66 \mathrm{El}$ autor tiene derecho a prohibir la distorsión o cualquier otra afectación de su obra que sea capaz de perjudicar sus legítimos intereses intelectuales o personales sobre su obra (Urheberrechtsgesetz, traducción libre del autor). 
embargo, se entendió que ese derecho debía ser armonizado con los del propietario del inmueble, en este caso la galería de arte, que conserva la libertad de modificar arquitectónicamente su propiedad. Hay un interés público en el derecho del autor a la continuidad de su obra, pero se debe tener en cuenta el derecho del museo a modificar sus instalaciones y zonas de exposición, incluyendo rediseño o demolición del edificio. Si el artista hubiera pretendido que su obra no fuera modificada, trasladada o destruida, debería haberlo acordado por contrato.

Como surge del fallo bajo comentario, una primera sugerencia sería acudir a contratos y buenas prácticas, de modo de armonizar los derechos del museo y del artista. Por ejemplo, regulando contractualmente las obligaciones de mantenimiento, qué sucede en caso de ruina o vandalismo, si es posible que la obra sea trasladada o removida, si el autor ejercerá por sí mismo los derechos de reproducción, si se hará cargo de la eventual restauración o autorizará a terceros, entre otros aspectos ${ }^{67}$. Lamentablemente estos contratos son infrecuentes, cuando algunas estipulaciones podrían anticipar muchos problemas, como el cambio de dueño de la propiedad, quien hará las restauraciones, la autorización anticipada de la demolición o la facultad del artista de retirar la obra ${ }^{68}$.

En el derecho estadounidense, de acuerdo con la Visual Artists' Rights Act (VARA), la modificación de una obra de arte visual como consecuencia de trabajos de conservación o de su presentación al público, incluyendo la posición e iluminación, no puede interpretarse como destrucción o mutilación, salvo que la modificación sea causada por grave negligencia ${ }^{69}$. Aquí se estableció una regla que pretende armonizar intereses y derechos.

\section{DERECHO DE RETRACTO O RETIRADA}

El derecho de retracto o arrepentimiento es aquel "a través del cual un autor puede pedir el retiro de la obra o de sus ejemplares del comercio cuando, por un cambio de convicciones éticas, políticas, filosóficas o de cualquier otra índole, su permanencia o circulación contradiga gravemente la nueva ideología de su creador y por ende su prestigio o reputación" 70 . En lo que hace al derecho de retracto, se trata de una situación excepcional en el caso de obras plásticas, sobre la cual se

67 Cfr. Malaro y DeAngelis, A Legal Primer on Managing Museum Collections, p. 221.

68 De modo ejemplificativo, en la Dirección Nacional del Derecho de Autor de la República Argentina, desde 1934 a la fecha, solo hemos encontrado el registro de un solo contrato entre un muralista y el propietario del inmueble al que accedió la obra.

69 vara (Visual Artists' Rights Act), 17 U.S.C. S 106A(c)(2): “The modification of a work of visual art which is the result of conservation, or of the public presentation, including lighting and placement, of the work is not a destruction, distortion, mutilation, or other modification [...] unless the modification is caused by gross negligence". Cfr. Malaro y DeAngelis, $A$ Legal Primer on Managing Museum Collections, p. 219.

70 República Federal Mexicana, Suprema Corte de Justicia de la Nación, $1^{\text {a }}$ Sala, 2 de mayo de 2012, Amparo Directo 11/2011, con comentario de Ricardo Antequera Parilli, disponible en https://aplicaciones.cerlalc.org/derechoenlinea/dar/index.php?mode=archivo\&id=2416, p. 55, última visualización 28 de enero de 2020. 
han expedido algunas legislaciones, como la española, la alemana, la italiana o la francesa, pero no ha sido previsto en el Convenio de Berna ${ }^{71}$. En nuestra región las referencias son mínimas, aunque algunas legislaciones han reglamentado el ejercicio del derecho de retracto de modo genérico, como Colombia, que en el artículo 30 de la Ley 23 de 1982 indica que el autor debe "indemnizar previamente a terceros de los perjuicios que se les pudiere ocasionar"72. He aquí un elemento común a todas las legislaciones que consideran este derecho: su ejercicio supone que el autor indemnice a los titulares del derecho de explotación ${ }^{73}$.

Otros sistemas indican expresamente que el derecho solo puede ser ejercido por el autor en vida y no por sus herederos luego de su muerte ${ }^{74}$. Así, el artículo 21 de la Ley Federal de Derecho de Autor de México establece que "Los titulares de los derechos morales podrán en todo tiempo: [...] v. Retirar su obra del comercio [...]", para luego aclarar que esa facultad no puede ser ejercida ni por los herederos ni por el Estado ${ }^{75}$. En los Estados Unidos de América se niega de modo expreso el derecho de retracto para las artes visuales ${ }^{76}$.

La situación resulta posible, y un autor podría reclamar que alguna de sus obras sea retirada de la exhibición del museo ${ }^{77}$. En otro tipo de obras, como las literarias, el retracto implicaría retirar la edición de circulación, pero sin efectos sobre los ejemplares ya distribuidos; es una solución que resulta armonizadora de los derechos de todas las partes. No sucede igual con las obras de ejemplar único.

En el caso de obras plásticas en posesión de un museo, el artista puede solicitar que se retire la obra del catálogo o de las salas de exhibición, justificando su pedido e indemnizando. El museo no podría limitar contractualmente esta facultad del artista ya que es irrenunciable. Ahora bien: si el museo la adquirió, ¿¿debe devolver el ejemplar y solicitar que se le reintegre el importe? Y si la recibió en donación, ¿debería devolver el ejemplar al donante? Es lícito interpretar que el museo cumple reservando la obra en depósito, ya que el interés del autor es que cese la divulgación. No hay una solución evidente, y resulta excesivo obligar a la entrega del ejemplar

71 Cfr. Ortega Doménech, Obra plástica y derechos de autor, p. 434.

72 Guzmán, Derecho del Arte, p. 85. En la legislación española, el artículo 14 inciso 6 del Real Decreto Legislativo 1/1996, de 12 de abril, indica que el autor puede "Retirar la obra del comercio, por cambio de sus convicciones intelectuales o morales, previa indemnización de daños y perjuicios a los titulares de derechos de explotación”.

73 Cfr. Lipszyc, Delia, Derecho de autor y derechos conexos, Unesco-Cerlalc-Zavalía, Buenos Aires, 2006, p. 172 .

74 Antequera Parilli, Estudios de derechos de autor y derechos afines, p. 90. La legislación mexicana, en el artículo 21 de la Ley Federal de Derecho de Autor, expresamente veda el ejercicio de ese derecho a los herederos o al Estado.

75 Elizalde Perdiz, Rosalba, comentario al artículo 21 Lfda, en Ley Federal de Derecho de Autor, comentada por la Asociación Mexicana para la Protección de la Propiedad Intelectual (mppi), Miguel Ángel Ortiz Bahena (coordinador), Editorial Porrúa, CDMx, 2017, p. 95.

76 Cfr. The Register of Copyrights, Waiver of Moral Rights in Visual Artworks, Final Report, Washington, marzo de 1996, p. 1, donde se exponen las consideraciones de la Visual Artists Rights Act of 1990, de diciembre de 1990, y que modifica la Copyright Act - 17 U.s.C. $\$ \$$ 101-1010, adicionando la Section 106 a.

77 Goldstein, Paul y Hugenholtz, Bernt, International Copyright: Principles, Law and Practice, Oxford University Press, Nueva York, 2013, Third Edition, p. 367. 
al artista, ya que el derecho de arrepentimiento no es equivalente a una revocación de la propiedad, cualquiera haya sido el título de adquisición ${ }^{78}$.

La legislación francesa quiso prevenir el ejercicio fraudulento del derecho de retracto, como modo de revocar una cesión legítima para luego volver a poner la obra en el comercio en mejores condiciones económicas. Si la obra retirada se vuelve a poner a la venta, tiene prioridad quien fuera el primer cesionario, en las mismas condiciones originales ${ }^{79}$. Entiendo que es una solución armónica que considera los intereses de todas las partes, incluyendo el del público. Es razonable que se exija un arrepentimiento estable para prevenir que el autor vaya mudando de opinión una y otra vez, en este caso en perjuicio del museo. La mudanza en las convicciones intelectuales y morales, si bien es una manifestación de la libertad de expresión, no puede ser ejercida de modo que afecte los derechos de terceros.

Como puede verse, he aquí otro aspecto de la relación entre artistas y museos que merecería reglas más claras que las actuales.

\section{DERECHOS PATRIMONIALES}

Los derechos patrimoniales conforman una constelación integrada por todas las posibles explotaciones o usos de la obra, que requieren autorización del autor. Más allá de los nombres específicos con que se denomine en cada legislación a los derechos que tiene el autor sobre su obra, esta puede ser utilizada o explotada mediante la reproducción o copia, la distribución de las reproducciones o copias, la comunicación pública y la transformación. Cada una de estas modalidades a su vez puede subdividirse en tantas otras formas como la tecnología y el mercado requiera, debido a que no se trata de un numerus clausus. Todos ellos permiten al autor o titular de derechos a ejercer un control sobre su obra de tal modo que puede excluir de su uso a terceros o determinar bajo qué modalidad podrán hacerlo, sea onerosa o gratuita ${ }^{80}$.

Ante la enorme diversidad de situaciones, solo señalaré algunos de los problemas que surgieron recientemente en la relación entre los museos y los artistas. Cuando la actividad se "desmaterializa" del ejemplar, ya no estamos ante el derecho de

78 Cfr. Ortega Doménech, Obra plástica y derechos de autor, p. 442. También Marín López, El conflicto entre el derecho moral..., p. 213 y ss.

79 El Código de la Propiedad Intelectual de Francia establece en su artículo L121-4: "Aunque haya cedido el derecho de explotación, el autor, incluso con posterioridad a la publicación de su obra, gozará del derecho de revocación o de retracto con respecto al cesionario. Sin embargo, podrá ejercer dicho derecho siempre y cuando indemnice previamente al cesionario por el perjuicio que esta revocación o este retracto le pudiera causar. Cuando el autor decida publicar su obra con posterioridad al ejercicio de su derecho de revocación o de retracto, deberá ofrecer con prioridad sus derechos de explotación al cesionario que había elegido originariamente y en las condiciones originariamente pactadas". Traducción disponible en la página de la OMPI, https:/www.wipo.int/edocs/lexdocs/laws/es/fr/fr467es.pdf, última visualización del 6 de febrero de 2020. El artículo 14.6 de Ley de Propiedad Intelectual de España contiene una disposición equivalente.

80 Cfr. Lipszyc, Derecho de autor y derechos conexos, p. 175 y ss. 
exhibición sino de reproducción, comunicación al público, puesta a disposición o inclusión, entre los principales ${ }^{81}$. Así, por ejemplo, no trataré el derecho de seguimiento o droit de suite, porque si bien resulta de suma relevancia para los autores, no entiendo que presente conflictos respecto de los museos, que en caso de adquisiciones deberán asegurarse de que llegue al artista o sus herederos la parte correspondiente del valor de compra, al igual que cualquier otra adquisición de obra de arte, en los términos considerados por la legislación nacional respectiva ${ }^{82}$.

La actividad tradicional de los museos se sustenta esencialmente en la exhibición, que se rige por las normas del territorio donde se localiza el establecimiento. Pero como los derechos son territoriales, cada uno será ejercido de modo independiente en cada jurisdicción nacional. De aquí que habrá que estar advertidos de las dificultades que podrían presentar, entre otras situaciones, las muestras itinerantes transfronterizas, en las que se deberá verificar el cumplimiento de las normas del país receptor.

Para la gestión de su acervo, el museo deberá primero determinar el carácter de obra protegida respecto de cada una de las piezas que forman parte del patrimonio del museo. Luego, en caso de que lo sean, si están en el dominio público o privado. Algunos derechos corresponderán al autor o sus sucesores; otros, al museo; otros, a terceras partes. También será importante determinar a qué género pertenecen las obras: pintura, grabado, fotografía, audiovisual, efímera. De esto depende el plazo de vigencia de los derechos o los posibles titulares, o el carácter de original de cada ejemplar, entre otros aspectos.

\section{A. PRIMERA DEFINICIÓN: EL DERECHO DE AUTOR SOLO SE APLICA A LAS OBRAS}

Sin entrar en el debatido asunto respecto de cuándo estamos ante una obra de arte, sí cabe aclarar que algunas piezas no son obras desde el punto de vista del derecho de autor. Así, cualquier objeto que no presente originalidad, donde no se manifieste la impronta creativa del autor, no será obra ${ }^{83}$. Hay muchos museos que contienen

81 Distintas legislaciones nacionales establecen expresamente esta disociación entre el derecho real sobre la cosa y el derecho de autor sobre la obra plasmada en el soporte. A modo de ejemplo, la Ley de Propiedad Intelectual de España, artículo 3, indica: "Los derechos de autor son independientes, compatibles y acumulables con: $1 .^{\circ} \mathrm{La}$ propiedad y otros derechos que tengan por objeto la cosa material a la que está incorporada la creación intelectual [...]". Cfr. Ortega Doménech, Obra plástica y derechos de autor, p. 311.

82 En la UE están exentos del droit de suite las reventas efectuadas directamente entre personas que actúen a título privado sin la participación de un profesional del mercado del arte, lo que incluye a quienes actúen a título privado revendiendo a museos no comerciales abiertos al público. Cfr. considerando 18 de la Directiva 2001/84/CE del Parlamento Europeo y del Consejo, del 27 de septiembre de 2001, relativa al derecho de participación en beneficio del autor de una obra de arte original. Respecto del droit de suite y museos, cfr. Vicente Domínguez, Elena, "Derechos de autor en la venta y el alquiler de la obra plástica", en Museos y Propiedad Intelectual, Carlos Rogel y Andrés Domínguez (directores), Reus, Madrid, 2012, p. 62 y ss.

83 Toda obra goza de la protección del derecho de autor, bajo la única condición de que resulte original y fruto de la actividad creativa del artista. Se trata de una presunción iure et de iure y no se requiere valoración estética o mérito. Cfr. Ortega Doménech, Obra plástica $y$ derechos de autor, p. 23 y ss. 
piezas de valor arqueológico, paleontológico, histórico o tecnológico, entre otras tantas disciplinas que estudian y coleccionan elementos y sustancias que no están cubiertas por el derecho de autor. Carruajes y otros vehículos, vestimenta, utensilios de uso cotidiano, meteoritos, plantas y animales, equipamiento técnico... La lista sería interminable. En algunos casos abarca toda una categoría; en otras, hay que hacer distinciones. El hecho de que no estemos ante una obra podría plantear si se aplican otras normas, como las del patrimonio cultural, regulaciones sobre recursos genéticos o sobre bienes pertenecientes a pueblos originarios, entre otras ${ }^{84}$.

Respecto de las obras de arte, originalidad y valor artístico no son sinónimos, ya que el derecho de autor no se deriva del mérito, la calidad o la técnica ${ }^{85}$. Solo es relevante la impronta personal del autor, su aporte creativo, representado en la forma expresiva mediante la cual plasmó su idea estética. De aquí que se pueda distinguir al autor del artesano ${ }^{86}$. Así, cuando una pieza de mobiliario estandarizada es intervenida por un artista o bien el diseño resulta original, se les aplicará el régimen propio del derecho de autor, derivándose derechos morales y patrimoniales ${ }^{87}$.

Vale la pena recordar uno de los antecedentes más difundidos sobre este tópico, que tuvo como protagonista al escultor húngaro Constantin Brancusi. En 1926 arribó por buque a la ciudad de New York con veinte de sus esculturas, como parte de una exposición. El funcionario de aduanas consideró que no se trataba de arte, estableciendo en consecuencia que no se debía aplicar la exención del tributo aduanero destinado a piezas artísticas y ordenó que se pagara el impuesto ordinario, como si se tratara de un electrodoméstico. Brancusi tuvo que demostrar ante los tribunales y con el auxilio de peritos que su escultura, de bronce dorado y pulido, era una obra de arte. El magistrado concluyó que el arte abstracto es arte, cuando hasta esa época estaba vigente el criterio de considerar arte solo al figurativo.

En definitiva, la preocupación de los museos respecto del uso de elementos de sus colecciones o depósitos solo se refiere a las obras protegidas por el derecho de autor. La observación no es menor, ya que en distintas ocasiones se ha hecho referencia a la incertidumbre que representa la exhibición de documentos y elementos diversos. Si los documentos son oficiales, emitidos por la autoridad del Estado, aun cuando sean originales no se aplica la protección autoral ${ }^{88}$.

84 Cfr. Malaro y DeAngelis, A Legal Primer on Managing Museum Collections, p. 93 y ss. Lima, Guía de Buenas Prácticas..., pp. 86 y ss.

85 Prieto de Pedro, Jesús "Cuando los tribunales definen el arte o una escultura que no era un utensilio de cocina: el caso Brancusi", Derecho del Arte, Anuario Iberoamericano 2016, Civitas-Thomson Reuters, Madrid, 2016, p. 423 y ss.

86 Respecto de la distinción entre autor y artesano y por tanto entre obra y artesanía, cfr. Casas Vallès, Ramón "Los casos Barceló y Boadella", Doctrina IIDA, 2008 (disponible en http:// iidautor.org/doctrina.html, última visualización 27 de enero de 2020), comentando el fallo de la Audiencia Provincial de Palma de Mallorca, Sección 5a sentencia n. ${ }^{\circ}$ 24, Recurso de Apelación 638/2006, publicada por el Cerlalc, https://cerlalc.org/wp-content/uploads/dar/jurisprudencia/1393.pdf.

87 De modo general para la aplicación de los criterios jurídicos respecto del derecho de autor sobre las obras de arte y en particular la originalidad, cfr. Guzmán, Derecho del Arte, pp. 25-60.

88 Se trata de una disposición del Convenio de Berna, de aplicación generalizada en todos los países. "Artículo 2. 4) Queda reservada a las legislaciones de los países de la Unión la facultad 


\section{B. EL DERECHO DE EXHIBICIÓN Y LOS MUSEOS}

Conforme a su misión y objetivos, lo más relevante para un museo será contar con el derecho de exhibición de las obras en él contenidas. Parece connatural a su actividad que se pueda poner en conocimiento del público aquellas piezas que conforman su patrimonio. De aquí surgen diversas cuestiones. Damos por supuesto que el museo tendrá título suficiente sobre el soporte material que constituye la obra, y en muchos casos de ejemplar único, ya sea en propiedad o tenencia, proveniente de una adquisición, donación o legado, sea usufructuario, depositario o comodatario ${ }^{89}$. Pero eso no significa que tenga los derechos de autor sobre la obra, ya que los derechos derivados de la inmaterialidad son diversos de aquellos propios de los bienes muebles" ${ }^{\prime \prime 0}$.

El derecho de exhibición o exposición es una especie de la comunicación pública, realizada de modo directo a un público que se encuentra presente, ya sea del ejemplar único o de uno de sus ejemplares originales (en caso de ejemplares múltiples) o bien de una réplica elaborada por el mismo autor ${ }^{91}$. Por aplicación de los principios generales, el dominio o tenencia del ejemplar no significan por sí mismos la transferencia de los demás derechos, salvo supuestos expresos de cesión legal ${ }^{92}$. Así, por ejemplo, el artículo 56 párrafo 1 de la Ley de Propiedad Intelectual de España, ya citado. Pero aun así, los derechos de exhibición no incluyen los derechos de reproducción en catálogos ni el derecho a incluirlo en una obra audiovisual.

La Ley Federal de Derechos de Autor de México prevé una solución similar. Si bien el artículo 27 establece para el autor el derecho exclusivo de autorizar o prohibir la exhibición pública de la obra por cualquier medio o procedimiento, luego el artículo 85 indica que "Salvo pacto en contrario, se considerará que el autor que haya enajenado su obra pictórica, escultórica y de artes plásticas en general, no ha concedido al adquirente el derecho de reproducirla, pero sí el de exhibirla y el de plasmarla en catálogos. En todo caso, el autor podrá oponerse al ejercicio de estos derechos, cuando la exhibición se realice en condiciones que perjudiquen su honor o reputación profesional".

Algo similar ocurre en la legislación estadounidense. Así, en la sección 106 (5) de la Copyright Act se establece el derecho exclusivo del autor a exponer públicamente

de determinar la protección que han de conceder a los textos oficiales de orden legislativo, administrativo o judicial, así como a las traducciones oficiales de estos textos".

89 Dejamos de lado el "título suficiente" por no ser objeto de este trabajo, aunque su relevancia no debe ser despreciada. Cabe mencionar, por ejemplo, la responsabilidad del museo por poseer obras robadas, provenientes de contrabando o que sean botín de guerra. Cfr. Malaro y DeAngelis, A Legal Primer on Managing Museum Collections, pp. 83 y 122.

90 "Los derechos de autor y los derechos sobre la cosa en que se materializa la obra intelectual o artística son distintos, y pueden tener diferente titular, versar sobre distinto objeto (la cosa corporal en un caso, la obra intelectual, ente espiritual, en otro), y tienen distinto contenido e independencia en sus vicisitudes". Rivero Hernández, "Reproducción de la obra plástica propiedad de museos y colecciones privadas”, p. 1166.

91 Cfr. Lipszyc, Derecho de autor y derechos conexos, p. 185.

92 Cfr. Guzmán, Derecho del Arte, p. 99, donde citan las legislaciones alemana, portuguesa y española. 
la obra o sus copias o reproducciones, incluyendo la comunicación pública por televisión y cualquier otro medio. Luego, en la sección 109, se establece que, sin perjuicio de lo establecido en la sección 106 (5), el propietario del original o una copia válidamente obtenida, o un tercero bajo su autorización, tiene el derecho de exhibirla públicamente en el lugar donde la copia se encuentra físicamente. Queda establecido que se trata de un derecho del propietario, que no se puede extender a quien tenga la obra en préstamo, alquiler o depósito ${ }^{93}$.

En el caso de la Ley 11.723 de la República Argentina, el artículo 2. ${ }^{\circ}$ establece que "El derecho de propiedad de una obra científica, literaria o artística comprende para su autor la facultad de [...] exponerla en público [...]”. A lo que el artículo 54 agrega: "La enajenación o cesión de una obra pictórica, escultórica, fotográfica o de artes análogas, salvo pacto en contrario, no lleva implícito el derecho de reproducción que permanece reservado al autor o sus derechohabientes" ${ }^{\prime 4}$.

La situación del artista es delicada ${ }^{95}$. Si exige sus derechos de conservar el control sobre la exhibición, es probable que el museo no adquiera la obra. Sería distinto si lo vende a un coleccionista privado, que tal vez no esté actualmente interesado en exhibirla, aun cuando la obra pierda valor potencial si no puede ser exhibida por un tercer adquirente posterior ${ }^{96}$. Por parte del museo, no parece razonable que corra el riesgo de adquirir una obra sin el derecho de exhibirla. Sí parece de interés del museo comprometerse a facilitar la obra a pedido del autor, si este o terceros organizaran una muestra retrospectiva del artista. Dicho compromiso podría estar condicionado a circunstancias de tiempo y espacio, de seguridad y onerosidad.

93 Cfr. Merryman et al., Law, Ethics and the Visual Arts, pp. 544-545. La norma mencionada dice así: "\$109 Limitations on exclusive rights: Effect of transfer of particular copy or phonorecord. (c) Notwithstanding the provisions of section 106(5), the owner of a particular copy lawfully made under this title, or any person authorized by such owner, is entitled, without the authority of the copyright owner, to display that copy publicly, either directly or by the projection of no more than one image at a time, to viewers present at the place where the copy is located. (d) The privileges prescribed by subsections (a) and (c) do not, unless authorized by the copyright owner, extend to any person who has acquired possession of the copy or phonorecord from the copyright owner, by rental, lease, loan, or otherwise, without acquiring ownership of it".

$94 \mathrm{Si}$ bien la enajenación del soporte de una obra de arte no implica la autorización para reproducirla, la jurisprudencia entendió que el museo que adquiere el soporte de una obra puede exhibirla de modo gratuito u oneroso. Cfr. "Societé des Auteurs dans les Arts Graphiques et Plastiques c/ Asociación Amigos del Museo Nacional de Bellas Artes y otros/propiedad intelectual Ley 11.723", Cámara Nacional de Apelaciones en lo Civil de la Capital Federal, Sala J, 14 de agosto de 2006. Disponible en https://aplicaciones.cerlalc.org/derechoenlinea/dar/ index.php? mode=info\&id $=1487$ Pero la doctrina no es pacífica al respecto. Cfr. Lipszyc, Régimen Legal de la Propiedad Intelectual, p. 366.

95 Respecto de esta delicada situación, es útil recordar los antecedentes que motivaron los cambios de la legislación española, primero declarando el derecho exclusivo a favor del artista, luego estableciendo la cessio legis a favor del adquirente. También ver el interesante análisis si el artista que vendió su obra debe participar de los ingresos generados por una exhibición que tenga fines de lucro. Cfr. Rogel Vide, Carlos, "Exposición pública de obras plásticas", en Museos y Propiedad Intelectual, Carlos Rogel y Andrés Domínguez (directores), Reus, Madrid, 2012, pp. 37 y 43.

96 Ortega Doménech, Obra plástica y derechos de autor, p. 318. 
Las soluciones del derecho español, mexicano y estadounidense, así como otras legislaciones, establecen una regla que favorece la actividad de los museos y los coleccionistas. Si bien puede significar un perjuicio para algunos artistas, propicia un mercado dinámico del arte, en beneficio del colectivo de artistas. Por otra parte, la exhibición favorece al autor, aumentando su prestigio y la difusión de su producción. La ausencia de reglas debería ser un llamado de atención para aquellos museos, como los de Argentina, en la medida en que adquieran obras sin seguridad jurídica respecto de esos ejemplares.

Por supuesto que la ausencia de reglas se puede solucionar mediante la imposición de condiciones contractuales a los artistas, pero bajo el riesgo de que esas condiciones puedan ser consideradas un abuso respecto de los autores ${ }^{97}$. Además, esas condiciones contractuales, que raramente existen, deberían ser oponibles a terceros mediante la publicidad del contrato, de tal modo que sean respetadas por adquirentes sucesivos ${ }^{98}$. Por otra parte, si el museo adquirió la obra directamente del autor y este se niega a que sea exhibida, sería un típico caso de incumplimiento de los deberes de buena fe del contratante ${ }^{99}$. Otro tanto si el museo adquirió la obra de un tercero; aquí la negativa a la exhibición por parte del artista llevaría a la resolución del contrato por la frustración del fin en vistas del cual se celebró ${ }^{100}$.

El derecho de exhibición plantea otros problemas, como, por ejemplo, si existe una obligación del museo de exhibir la obra o puede tenerla en depósito ${ }^{101}$. O si el derecho de exhibición puede ser ejercido por un tercero organizador de la exposición pero que no es el propietario de la obra de arte. En conclusión, se requiere aportar al sistema algunas reglas que superen la inestable situación presente. De

97 Así se manifestó el informe "Dorothy M. Weber of the Visual Artists and Galleries Association of the United States”, en el que se puso de manifiesto que los museos abusaban, en la práctica, de los derechos de los artistas. Cfr. Rivero Hernández, "Reproducción de la obra plástica propiedad de museos y colecciones privadas”, p. 1151.

98 Sobre la ausencia de contratos en las compraventas de arte, cfr. Vicente Domínguez, “Derechos de autor en la venta y el alquiler de la obra plástica”, p. 57.

99 Código Civil y Comercial de la República Argentina, "Artículo 961. Buena fe. Los contratos deben celebrarse, interpretarse y ejecutarse de buena fe. Obligan no sólo a lo que está formalmente expresado, sino a todas las consecuencias que puedan considerarse comprendidas en ellos, con los alcances en que razonablemente se habría obligado un contratante cuidadoso y previsor".

100 Código Civil y Comercial de la República Argentina, "Artículo 1090. Frustración de la finalidad. La frustración definitiva de la finalidad del contrato autoriza a la parte perjudicada a declarar su resolución, si tiene su causa en una alteración de carácter extraordinario de las circunstancias existentes al tiempo de su celebración, ajena a las partes y que supera el riesgo asumido por la que es afectada. La resolución es operativa cuando esta parte comunica su declaración extintiva a la otra. Si la frustración de la finalidad es temporaria, hay derecho a resolución sólo si se impide el cumplimiento oportuno de una obligación cuyo tiempo de ejecución es esencial”.

101 Hay autores que entienden que mantener la obra fuera de exhibición sería contrario a la finalidad del contrato y que por tanto el autor puede exigir el cumplimiento de este, aplicando un criterio de interpretación teleológico. Cfr. Ruipérez de Azcárate, "El derecho de autor y sus límites: una encrucijada para los museos", pp. 100-101. Entiendo que se podría llegar a una conclusión similar acudiendo a la "causa fin" del contrato, en la medida que hubiera sido puesta de manifiesto por las partes. 
lo contrario, es inevitable la colisión entre el principio de independencia de los derechos y el derecho de propiedad sobre el bien material ${ }^{102}$.

\section{LAS INSTALACIONES, ENTRE EL DERECHO DE AUTOR \\ Y EL DERECHO SOBRE LAS COSAS}

Otra dificultad se plantea con las creaciones denominadas "instalaciones", constituidas por montajes de duración temporal determinada. La instalación es de valor artístico equivalente a la obra arquitectónica o escultórica, aunque sin permanencia. Los elementos que la conforman están dispuestos de un modo particular, generando un efecto estético perceptible por los sentidos del público, en ocasiones interactuando con la luz, el sonido, el movimiento, el espacio o la perspectiva. Incluso, a veces son elementos comunes donde la forma expresiva es esa particular disposición.

A diferencia de la escultura tradicional, que es fija y estática, aunque pueda ser trasladada, la instalación posee movilidad y una disposición específica para el armado. Los museos deben ser precavidos, ya que la falta de uno de los elementos o la organización espacial que no respete la voluntad del autor puede afectar sus derechos morales y patrimoniales. Las reglas del arte para preservar las instalaciones se refieren al ensamble y cuidado de las piezas, evitando el deterioro. Parece que las contingencias tienen relación con el derecho sobre las cosas, pero sin embargo afectan también el derecho de autor cuando la instalación puede perder su condición de obra de arte, convirtiéndose en una superposición de elementos sin sentido ${ }^{103}$.

No sería el caso de las obras de arte efímeras, cuando por el tipo de materiales o la estructura que la soporta se pudiera prever que el deterioro será una consecuencia natural del paso del tiempo o del uso normal de dicha obra de arte.

\section{OBRAS DERIVADAS, FOTOGRAFÍAS Y OTRAS}

REPRODUCCIONES DE OBRAS EN DOMINIO PÚBLICO

Los derechos de autor tienen una vigencia temporal, que en Argentina de modo general es de setenta años post mortem, pero con plazos especiales para la fotografía, las obras cinematográficas y las obras anónimas creadas por organismos públicos. Luego de ese período, la obra pasa al dominio público.

Se ha cuestionado si una reproducción o una obra derivada de una obra en el dominio público o una interpretación u otro derecho conexo como un fonograma o la señal radiodifundida que contienen una obra en el dominio público implican que esa obra vuelve al dominio privado. La respuesta negativa se impone. La obra originaria, por contraposición a derivada, así como los demás supuestos enumerados, permanece en el dominio público. La obra derivada o la adaptación es en

102 Cfr. Guzmán, Derecho del Arte, pp. 99-101.

103 Cfr. Bustamante Alsina, Jorge, "El contrato de exhibición de obra de arte es atípico e innominado. Responsabilidad del expositor", Revista Jurídica La Ley 1997-F-649. 
sí misma una nueva obra, que tendrá su propio plazo de vigencia, en la medida en que cumpla con el requisito básico de cualquier obra, es decir la originalidad en cuanto aporte creativo personal del autor de la obra derivada o adaptada ${ }^{104}$.

De este modo, las fijaciones de interpretaciones o la inclusión de obras en el dominio público en señales de radio o televisión no significan un regreso de la obra al dominio privado. Otro tanto sucede si se elabora un documental u otra obra audiovisual utilizando las imágenes de las obras. Esas obras siguen en el dominio público para ser interpretadas por otros o bien ser incluidas en nuevos audiovisuales, o para que otros organismos de radiodifusión las ensamblen en sus propias señales portadoras de programas.

Un caso que ha adquirido importancia para los museos son las fotografías autorizadas de las obras de arte y que luego están disponibles en sitios virtuales o son incorporadas a obras audiovisuales o publicaciones ${ }^{105}$. La fotografía, como obra, es independiente respecto del objeto fotografiado y de diferente valor artístico ${ }^{106}$. Si bien la fotografía es un caso de reproducción de la obra, no debe entenderse como una copia. La copia es un tipo de reproducción en que se confecciona un ejemplar que conserva las características físicas del original, mientras que la fotografía es una representación menguada de la pieza ${ }^{107}$. Incluso se ha discutido si la fotografía podría considerarse una reproducción, en la medida en que no cumple con una de sus características esenciales, como es la repetición con fidelidad o exactitud de los elementos y caracteres del original ${ }^{108}$.

En algunos casos se cuestionó que los museos ejercitaran los derechos de autor sobre las fotografías de obras de arte en el dominio público porque sería una nueva privatización de esa obra de arte por vía indirecta ${ }^{109}$. Cabe mencionar dos

104 Cfr. Navas Navarro, Susana, "Integridad y transformación de obras que se encuentran en el dominio público. En tono a su apropiación en exclusiva por terceros", en Carlos RogeL (dir.), Los derechos morales de los creadores, Reus, Madrid, 2019, pp. 223-251.

105 Crews, Kenneth D. y Brown, Melissa A., "Control of museum art images: the reach and limits of copyright and licensing”, en The Structure of Intellectual Property Law. Can One Size Fit All? Annette Kur y Vytautas Mizaras (ed.), Edward Elgar, Cheltenham, 2011, pp. 269-270.

106 "Las obras, al entrar en un plano digital de registro, adoptan características estéticas y simbólicas como cualquier otra imagen. No son consideradas como al igual que la obra ya que no pueden producir una experiencia transformadora. Su soporte, su materialidad y su escala, queda lavada en pos del registro, por lo tanto, hay una parte del discurso que falta. No pasa así con las obras en las cuales coincide su formalidad con el soporte exhibido desde las intenciones del autor" (sic). Entrevista a la artista Brenda Puleston.

107 Un caso evidente de copias son las reproducciones a tamaño original que se utilizan para la formación de artistas, como las existentes en el Museo de Calcos y Escultura Comparada Ernesto de la Cárcova, de la Universidad Nacional de las Artes, en la Ciudad de Buenos Aires. Cfr. https://museodelacarcova.una.edu.ar/.

108 Cfr. Rivero Hernández, "Reproducción de la obra plástica propiedad de museos y colecciones privadas”, p. 1161. Este autor se pregunta si una fotografía o un video de La Pietá de Michelangelo puede ser considerado una reproducción, y afirma que solo en sentido figurado se puede hablar en términos de reproducción "pues no puede proporcionar la misma homogeneidad física y representativa del original, ejemplar único que integra a la vez la obra de creación y su propia exteriorización o extrinsecación material en una unidad inescindible (cosa que no ocurre en la obra intelectual respecto de su corpus mechanicum)".

109 Crews, “Museum Policies...", p. 806. 
casos interesantes ${ }^{110}$. En el primero, National Portrait Gallery (UK) v. Wikimedia Commons, un estudiante descargaba las fotografías del sitio virtual del museo y las reproducía y ponía a disposición en otras plataformas de acceso abierto. El museo se opuso bajo el argumento de que se afectaban los derechos exclusivos del fotógrafo y del museo. La respuesta fue que el museo no tenía el derecho de reproducción sobre la obra sino un derecho real sobre del soporte, derivado de la propiedad mueble. El caso se debatió intensamente en los medios y las redes sociales, pero no llegó a los tribunales.

El segundo caso es Bridgeman Art Library, LTD. v. Corel Corp. Corel vendía un CD-ROM con imágenes de obras de arte de grandes maestros europeos. Bridgeman alegó ser el titular de esas imágenes digitales. El juez aplicó derecho inglés respecto de la originalidad de las fotografías por ser el primer lugar de publicación. Pero para determinar si había infracción debía aplicarse el derecho estadounidense, donde las reproducciones eran distribuidas. Respecto de la originalidad, el criterio fue el siguiente: "works need not be original or novel in form, but it must originate with the author and not be copied from another work". El juez entendió que las fotografías carecían de originalidad, por tratarse de copias fieles de obras de arte originales.

Como principio general, el esfuerzo técnico para ser fiel al original no implica originalidad y por tanto no puede ser considerado obra desde el derecho de autor $^{111}$. En la fotografía, no es suficiente el mero recurso técnico, sino que tiene que existir el aporte personal a través de decisiones creativas expresadas mediante la fotografía, que no pueden reducirse a una cuestión de enfoque e iluminación ${ }^{112}$.

Crews sostiene que estos criterios jurisprudenciales no son suficientes para salvar los conflictos que surjan entre museos y usuarios ${ }^{113}$. Así, en los países donde existe la distinción entre fotografía y la mera fotografía, las segundas tienen un plazo menor de protección y carecen de derechos morales. En otros casos los titulares solo tienen un derecho de remuneración ${ }^{114}$. La ley de derecho de autor debe evitar los efectos indeseados de un sistema que vaya más allá de aquello para lo cual fue

110 Ambos relatados y analizados por Petri, Grischka, “The Public Domain vs the Museum: The Limits of Copyright and Reproductions of Twodimensional Works of Art", Journal of Conservation and Museum Studies, 12(1), p. 8.

111 Cfr. Parets Gómez, Jesús, Originalidad, creatividad y registro del derecho de autor, Ed. Sista, Ciudad de México, 2018, p. 144 y ss.

112 Cfr. Garvin, Kaitlyn M. "Reclaiming Our Domain: Digitization of Museum Collections and Copyright Overreach", IDEA - The Law Review of the Franklin Pierce Center for Intellectual Property, vol. 59, n. ${ }^{\circ}$ 2, p. 455. Товón Franco, Natalia y Varela Pezzano, Eduardo, "Dos problemas jurídicos alrededor de las fotografías: la originalidad y el derecho a la intimidad", Revista Iberoamericana de la Propiedad Intelectual, n. ${ }^{\circ}$ 5, junio 2015, disponible en http:// ar.ijeditores.com/pop.php?option $=$ articulo $\&$ Hash $=9579 \mathrm{fbc} 152572 \mathrm{e} 82 \mathrm{a} 9 \mathrm{c} 71587 \mathrm{~d} 610 \mathrm{ee} 3 \mathrm{~d}$.

113 Cfr. Crews, “Museum Policies...", p. 808.

114 Texto Refundido de la Ley de Propiedad Intelectual de España, art. 128: "Quien realice una fotografía u otra reproducción obtenida por procedimiento análogo a aquélla, cuando ni una ni otra tengan el carácter de obras protegidas en el Libro I, goza del derecho exclusivo de autorizar su reproducción, distribución y comunicación pública, en los mismos términos reconocidos en la presente Ley a los autores de obras fotográficas. Este derecho tendrá una duración de veinticinco años computados desde el día 1 de enero del año siguiente a la fecha de realización de la fotografía o reproducción”. 
diseñado. Hay que considerar que los museos promueven el entorno creativo, y que hoy día tienen una misión más amplia que aquella que les dio origen.

Así lo prevé la reciente Directiva europea (UE) 2019/790 del 17 de abril de 2019 sobre los derechos de autor y derechos afines en el mercado único digital, que en su artículo 14, bajo el título "Obras de arte visual de dominio público", establece que "Los Estados miembros dispondrán que, cuando haya expirado el plazo de protección de una obra de arte visual, cualquier material resultante de un acto de reproducción de dicha obra no esté sujeto a derechos de autor o derechos afines, a menos que el material resultante de dicho acto de reproducción sea original en la medida en que sea una creación intelectual de su autor".

En la lógica del derecho de autor, solo tendrán protección las obras originales en dominio privado, o bien aquellas obras derivadas que resultan originales en sí mismas aun cuando reconozcan su dependencia respecto de otras obras originarias. De este modo, se aporta armonía a la posible tensión entre los intereses de los artistas, los museos y el público.

\section{EL PROCESO NORMATIVO MULTILATERAL EN EL ÁMBITO DE LA OMPI}

La armonización requerida también es motivo de debates en el ámbito internacional, siendo objeto de negociaciones multilaterales en el marco de la OMPI, como parte de las actividades del Comité Permanente de Derechos de Autor y Derechos Conexos (sCCR, en su acrónimo en inglés) ${ }^{115}$. Allí está abierto un espacio de discusión que, sin anticipar el resultado final, pretende lograr soluciones en el plano internacional. El proceso también involucra a las bibliotecas, los archivos $\mathrm{y}$ al ámbito educativo, ya que algunas de las situaciones son semejantes en todas estas instituciones.

\section{A. LIMITACIONES Y EXCEPCIONES PARA MUSEOS \\ EN EL ÁMBITO INTERNO DE LOS ESTADOS}

En la negociación referida hay distintas corrientes de opinión. Una de ellas es la promovida por los países desarrollados, que sostienen que cada país debe resolver los conflictos reglamentando sus propias limitaciones y excepciones, en el marco de lo establecido en los convenios internacionales vigentes. En virtud de la flexibilidad prevista en los instrumentos internacionales, los países tienen capacidad suficiente para reglamentar internamente las excepciones y limitaciones que consideren necesarias para armonizar el derecho de los autores con los requerimientos de los usuarios, en este caso los museos o sus visitantes.

115 Respecto del ámbito de negociación de los derechos de autor en la ompi, cfr. https:// www.wipo.int/policy/en/sccr/. Los principales documentos bajo consideración son los siguientes: SCCR/38/5, sCCR/37/6 y SCCR/30/2. 
Esta flexibilidad se asienta en la "regla de los tres pasos", que tuvo su origen en el Convenio de Berna. Esa regla permite a los países limitar el derecho exclusivo de reproducción y otros derechos, cuando esa reproducción no atente contra la normal explotación de la obra ni cause un perjuicio injustificado a los intereses legítimos del autor (Convenio de Berna, art. 9.2). En términos equivalentes, es parte de otros tratados internacionales, como el Tratado de la OMPI sobre Derecho de Autor (TODA), el Tratado de la OMPI sobre Interpretaciones y Ejecución de Fonogramas (TOIEF), el Tratado de Beijing y los ADpic ${ }^{116}$. La "regla de los tres pasos" es una enunciación específica del principio de razonabilidad o de proporcionalidad para el derecho de autor, pero que requiere concreción legislativa ${ }^{117}$. A la fecha, esto ha dado lugar a soluciones muy detalladas y otras casi inexistentes. La legislación argentina, por ejemplo, que ya de por sí contiene pocas limitaciones y excepciones, no contiene ninguna previsión específica para la actividad museística.

Los países en desarrollo, que en general no cuentan con industrias culturales propias que resulten sostenibles, prefieren establecer estándares uniformes en materia de limitaciones y excepciones y propugnan un tratado internacional vinculante, con un catálogo más amplio. Lo curioso es que muchos de esos países reclaman internacionalmente lo que no establecen en el ámbito interno, pudiendo hacerlo.

A raíz de esta importante diferencia de enfoque, las negociaciones en el marco de la OMPI se encuentran muy demoradas. Si bien los países desarrollados han aplicado con amplitud un régimen de limitaciones y excepciones para los museos, no son proclives a llevar al plano multilateral las soluciones ya implementadas en el ámbito interno o regional. La posición de los países desarrollados tiene su grado de razonabilidad. Si la República Argentina no tiene un mejor régimen para que los museos puedan cumplir con su misión y objetivos, al tiempo que se respete el derecho de los artistas, es problema de los argentinos, sin necesidad de acudir al auxilio de las organizaciones multilaterales. Además, las limitaciones y excepciones se insertan en un completo sistema sociojurídico, incluyendo el sentir cultural de la población por el respeto de las normas, el procedimiento judicial preventivo o represivo de las infracciones, el accionar de las fuerzas de seguridad, la consolidación de la gestión colectiva, por mencionar algunos aspectos.

116 Para un análisis detallado de la regla de los tres pasos, cfr. Córdoba Marentes, El derecho de autor y sus límites, p. 177. De la PARra Trujlllo, Derechos humanos y derechos de autor, p. 420. Por aplicaciones concretas a las obras de arte, cfr. Guzmán, Derecho del Arte, pp. 135 y ss.

117 Todas las limitaciones y excepciones deben cumplir con dichos requisitos. De modo expreso, en la conferencia de Roma de 1928, posterior al Convenio de Berna, se evitó establecer un criterio genérico. A tal fin se elaboró la "doctrina de las reservas menores" con implícitas excepciones de minimis, pero que deben cumplir con los elementos del artículo 9.2 del Convenio. Cfr. Ricketson, Sam, "Estudio sobre las limitaciones y excepciones relativas al derecho de autor y a los derechos conexos en el entorno digital", documento wiPo sCCR/9/7, 5 de abril de 2003, p. 57. 
En el estudio que Yaniv Benhamou preparó a pedido de la OMPI se enumeran las limitaciones y excepciones al derecho de autor halladas en las diferentes legislaciones nacionales en beneficio de los museos, a saber ${ }^{118}$ :

- Conservación de las obras.

- Sustitución de las obras.

- Reproducción de las obras con fines de archivo.

- Reproducción de las obras con fines de estudio e investigación.

- Exposición de obras tangibles.

- Exposición de obras audiovisuales con dimensión temporal ("exhibición in situ").

- Toma de fotografías por los visitantes en las instalaciones del museo.

- Exposición y puesta a disposición del público de colecciones y bases de datos de archivos en internet.

- Puesta a disposición en terminales.

- Uso de obras en catálogos de exposición.

- Uso de obras no atribuidas.

- Excepciones generales para los museos.

- Disposiciones y consideraciones adicionales respecto de las excepciones.

El mencionado estudio brinda un panorama sobre las distintas posibilidades legislativas que facilitarían un régimen de limitaciones y excepciones compatibles con el Convenio de Berna y los demás instrumentos internacionales aplicables a la materia. Las legislaciones de los países podrán distinguir los usos gratuitos bajo excepción, los usos remunerados bajo licencia o bajo remuneración compensatoria por copia privada.

Sin embargo, las limitaciones o excepciones en el plano local dejan sin resolver la actividad internacional de los museos, cuando el uso transfronterizo de obras tiene efectos multiterritoriales. Es un aspecto que requiere armonización de reglas internacionales, ya sea mediante la unificación o la coordinación. Es lo que planteó la República Argentina en la OMPI: un mecanismo que, sin perjuicio de las reglamentaciones nacionales, prevea reglas de coordinación para el ejercicio internacional de los derechos de autor y de los efectos de las limitaciones y excepciones ${ }^{119}$.

Respecto de los usos transfronterizos, un mecanismo que merece ser impulsado son las licencias multiterritoriales que implican representación recíproca o unilateral a cargo de una sociedad de gestión colectiva. Es un modo eficiente de facilitar algunos usos bajo remuneración. La gestión colectiva es necesaria para otorgar las

118 Benhamou, Yaniv, "Limitaciones y excepciones en materia de derecho de autor para los museos: análisis tipológico”, Documento wIPO scCR/38/6, 29 de marzo de 2019, disponible en https://www.wipo.int/edocs/mdocs/copyright/es/sccr_38/sccr_38_6.pdf.

119 Documento ompi SCCR 33/4, 1. ${ }^{\circ}$ de noviembre de 2016, disponible en https://www. wipo.int/edocs/mdocs/copyright/es/sccr_33/sccr_33_4.pdf. 
autorizaciones y percibir las recaudaciones en un territorio y luego distribuir esas sumas con los autores de esa u otras jurisdicciones. Es una práctica muy consolidada en otros géneros, como la música o el audiovisual, pero con menos tradición en las artes visuales y plásticas, al menos en nuestra región.

En el Seminario Regional para el Grupo de América Latina y el Caribe sobre Bibliotecas, Archivos, Museos e Instituciones Docentes y de Investigación, en el Ámbito del Derecho de Autor, celebrado en Santo Domingo, República Dominicana, los días 4 y 5 de julio de 2019, se consideraron algunas posibles soluciones que facilitarían esa armonización entre los autores, museos y el público. Compartiré aquí algunas de las propuestas debatidas en dicha reunión.

\section{B. PRESERVACIÓN DE LAS OBRAS}

Por diversas circunstancias, los museos necesitan realizar copias de preservación. Es una tarea que se identifica con los objetivos de la institución, ya sea por el deterioro de las obras, la necesidad de efectuar estudios o bien la obsolescencia de los soportes. Si el autor es extranjero, puede ser imposible obtener la autorización. La alternativa es que las copias de preservación estén autorizadas de modo expreso en la legislación, cumpliendo así con el requisito de la regla de los tres pasos. Como ya dije, lo que sería legítimo en sistemas que sostienen el fair use, no lo es en los sistemas jurídicos romano-germánicos ${ }^{120}$. Esa legislación debería establecer que la preservación no implica comunicación al público ni puesta a disposición de las copias. Se trata de una reproducción limitada a los fines específicos de su previsión. Así mismo, las copias de preservación deberían estar permitidas para todo tipo de obras: literarias, audiovisuales, fotográficas, musicales, artísticas, etc., ya que la actividad de los museos no distingue por géneros. La preservación también debería incluir la adaptación a otros formatos o salvaguardas para prevenir la obsolescencia de los soportes.

\section{PRESUNCIONES DE USO LEGÍTIMO EN CABEZA DE LOS MUSEOS}

La inclusión de una obra de arte en una nueva obra se suele realizar a través de una primera reproducción. Luego, la nueva obra, sea literaria, fotográfica, audiovisual, gráfica u otra obra plástica, por lo general será objeto de reproducción y comunicación al público. También suele ser necesario ejercer el derecho de transformación, ya que los cambios de género expresivo o de soporte material afectan ese derecho. Las posibilidades técnicas y expresivas son innumerables ${ }^{121}$.

120 Respecto del uso del fair use para legitimar las actividades de los museos en países de tradición anglosajona, cfr. Association of Art Museums Directors, Guidelines for the Use of copyrighted Materials and Works of art by Art museums, 2017, pp. 5 y 6. Malaro y DeAngelis, A Legal Primer on Managing Museum Collections, p. 185.

121 Estas posibilidades son explicadas en detalle por Iglesias Rebollo, César, "Inclusión de obras plásticas en otras obras", en Museos y propiedad intelectual, Carlos Rogel y Andrés Domínguez (directores), Reus, Madrid, 2012, pp. 77 y ss. 
Los sistemas jurídicos nacionales deberían contar con presunciones que faciliten el uso de obras y prestaciones por parte de los museos, en la medida que sea para cumplir con su misión institucional. Entiendo que se debe distinguir cuando la inclusión es realizada por el museo en posesión o tenencia legítima de la obra, de las situaciones en que la inclusión la realiza un tercero. A modo de ejemplo, la legítima posesión o tenencia del soporte debería incluir el derecho de exhibición, inclusión de la reproducción en catálogos, puesta a disposición de las fotografías en catálogos digitales, la inclusión en audiovisuales, streetview, etc. Se deberá considerar cuál es de la actividad concreta del museo al incluir la obra en otra y la finalidad perseguida.

También se debe distinguir la inclusión del legítimo uso del derecho de cita. Esta excepción, establecida en el artículo $10{ }^{\circ}$ del Convenio de Berna, ha sido objeto de reglamentación específica, aunque dispar, respecto de las obras de arte. Por ejemplo, la legislación española la prevé de este modo: "artículo 32. 1. Es lícita la inclusión en una obra propia de fragmentos de otras ajenas de naturaleza escrita, sonora o audiovisual, asi como la de obras aisladas de carácter plástico o fotográfico figurativo, siempre que se trate de obras ya divulgadas y su inclusión se realice a título de cita o para su análisis, comentario o juicio crítico. Tal utilización solo podrá realizarse con fines docentes o de investigación, en la medida justificada por el fin de esa incorporación e indicando la fuente y el nombre del autor de la obra utilizada"122.

Tanto el derecho de inclusión de las obras de arte en otras obras como la excepción del derecho de cita son temas que podrían solucionarse con reglas claras. Otro tanto se podría decir respecto de la titularidad de obras derivadas cuando sean elaboradas por encargo o en relación de empleo, como las fotografías de la colección. La titularidad en cabeza de la institución facilitaría la gestión de su patrimonio y de las actividades educativas o de divulgación que llevan adelante. Las presunciones mencionadas serían de exclusivo uso para los museos que tengan la obra en propiedad y solo para usos sin fines de lucro.

\section{ACCESO A LAS COLECCIONES POR PARTE DEL PÚBLICO}

Respecto de la licitud de la reproducción de las imágenes captadas por el público visitante, la situación no está prevista de modo expreso por la legislación de muchos países, como sucede en Argentina. Es una reproducción no autorizada expresamente por la ley, aunque el acto sea inocuo y socialmente aceptado, ya que no se advierte finalidad comercial. En los países anglosajones caería dentro de las previsiones del fair use o uso honesto. En el caso de las legislaciones de derecho continental, la excepción debe estar legislada, ya que la regla de los tres pasos exige su reglamentación. No se trata del ejercicio del derecho de cita, por faltar el fin de crítica o comentario. Desde otro punto de vista, parecería un acto tendiente al ejercicio de la libertad 
de expresión, donde el usuario manifiesta su agrado o admiración respecto de la creación artística, incluso favoreciendo el conocimiento y divulgación de las obras.

El uso y acceso a las colecciones de los museos por parte de terceros pueden regularse por buenas prácticas y reglamentos, pero también requieren cambios normativos. No pueden presumirse usos gratuitos ya que los artistas conservan sus derechos. Una posibilidad es que los derechos exclusivos se adapten a estas circunstancias y que, en lugar de autorizar y prohibir, sean compensados con una remuneración. De este modo el objeto de discusión se traslada a la cuestión presupuestaria, ya que quien debería hacerse cargo de esas remuneraciones son los museos que realizan las reproducciones o las autorizan al público.

\section{E. LA REMUNERACIÓN COMPENSATORIA POR COPIA PRIVADA}

Una solución viable al problema presupuestario es la remuneración compensatoria por copia privada, vigente en algunos países, pero que no se aplica sin más a la actividad museística. Es un mecanismo indirecto que traslada el costo de las reproducciones al usuario, siendo una aplicación del principio económico de la "internalización de los costos", por el cual paga quien se beneficia de una actividad determinada ${ }^{123}$.

Por este mecanismo, con la finalidad de armonizar los derechos de los titulares con las prácticas y necesidades del público, algunas legislaciones prevén una compensación por algunos tipos de usos. El Proyecto de Disposiciones Tipo de la OMPI, en su artículo 22, considera la remuneración por copia privada "la resultante de una licencia no voluntaria, que otorga un derecho de retribución económica a favor de los titulares de derechos a quienes perjudica la explotación de la obra a través de la copia privada" ${ }^{24}$.

Cualquier regla que se establezca deberá cumplir al menos con los dos elementos que caracterizan a la copia privada. Primero, que sea privada o individual, en el sentido que no sea para uso colectivo, comunitario o compartido. Luego, que sea sin fines de lucro, ya sea directo o indirecto. Así, el artículo artículo 41-2 de la ley francesa inhabilita "las copias de obras de arte destinadas a ser utilizadas para fines idénticos a aquellos para los que fue creada la obra original"125. En la Unión Europea, además de establecerse una excepción para las reproducciones que hagan los museos sin "intención de obtener un beneficio económico o comercial directo o indirecto”, también están autorizadas las reproducciones de los particulares

123 Para una explicación general de la “internalización de los costos", la "perfecta apropiabilidad" y otros conceptos de análisis económico aplicado a la propiedad intelectual, cfr. MAssot, Juan Miguel, "Análisis económico de los derechos de propiedad intelectual en semillas", en Innovación en propiedad intelectual en mejoramiento vegetal y biotecnología agricola, Miguel RAPELA y Gustavo Schöтz (coord.), Heliasta-Universidad Austral, Buenos Aires, 2006, pp. 63 y ss. 124 wipo, Documento CE/MPC/III/3, publicado en Copyright, Monthly Review of the World Intellectual Property Organization (wIPO) n. 9 September 1990, p. 272.

125 Cfr. Rivero Hernández, "Reproducción de la obra plástica propiedad de museos y colecciones privadas", p. 1186. 
personas físicas "para uso privado y sin fines directa o indirectamente comerciales, siempre que los titulares de los derechos reciban una compensación equitativa"126.

Entre los países de la región que han reglamentado la remuneración compensatoria por copia privada se puede mencionar a Paraguay y a la República Dominicana. En el primero, se establece la remuneración compensatoria en el artículo 34 de la Ley 1328/1998, aplicable a las copias efectuadas exclusivamente para uso privado y personal. El obligado al pago del canon es el fabricante nacional o importador de equipos y soportes contemplados en la reglamentación. Las obras plásticas están expresamente excluidas ${ }^{127}$.

República Dominicana prevé la copia privada en el artículo 37 de la Ley 65-00, del 21 de agosto de 2000. Allí tampoco está previsto el canon compensatorio para la reproducción de obras plásticas y visuales ${ }^{128}$.

La remuneración compensatoria requiere la consolidación de las sociedades de gestión colectiva que representan a los artistas visuales, lo cual plantea importantes desafíos en Latinoamérica.

\section{F. LA DIGITALIZACIÓN DE LAS COLECCIONES}

\section{Y LA APLICACIÓN DE LA LEX ORIGINIS}

Otro modo de facilitar el acceso y circulación de las obras, al tiempo que se respetan los derechos de los artistas, es brindar certeza respecto de cuál es el derecho aplicable a las reproducciones digitales de las obras, accesibles en múltiples jurisdicciones merced al uso de internet. En este sentido, "a los efectos que aquí interesan es reproducción no sólo la fijación en un soporte material con valor y finalidad reproductiva per se, en el sentido y términos vistos, sino también cuando esa fijación en tal soporte sea sólo un medio técnico necesario para la ulterior «comunicación pública» de la obra reproducida, propósito esencial y finalidad eminente de esta

126 Directiva 2001/29/CE del Parlamento Europeo y del Consejo, del 22 de mayo de 2001, relativa a la armonización de determinados aspectos de los derechos de autor y derechos afines a los derechos de autor en la sociedad de la información, artículo 5 inc. 2, apartados b y c.

127 Paraguay, Ley n. ${ }^{\circ}$ 1328/1998, artículo 34: "Los titulares de los derechos sobre las obras publicadas en forma gráfica, por medio de videogramas o en fonogramas, o en cualquier clase de grabación sonora o audiovisual, tendrán derecho a participar en una remuneración compensatoria por las reproducciones de tales obras o producciones, efectuadas exclusivamente para uso personal por medio de aparatos técnicos no tipográficos [...]. El artículo 44 excluye expresamente a las obras plásticas: "Es lícita la copia para uso exclusivamente personal de obras publicadas en forma gráfica, o en grabaciones sonoras o audiovisuales, siempre que se haya satisfecho la remuneración compensatoria a que se refiere el capítulo iv del título iv de la presente ley. Sin embargo, las reproducciones permitidas en este artículo no se extienden: [...] 2. a la reproducción integral de un libro, de una obra musical en forma gráfica, o del original o de una copia de las bellas artes, hecha y firmada por el autor [...]".

128 República Dominicana, Ley n. ${ }^{\circ}$ 65-00, artículo 37: “Es lícita la reproducción, por una sola vez y en un solo ejemplar, de una obra literaria o científica, para uso personal y sin fines de lucro, sin perjuicio del derecho del titular a obtener una remuneración equitativa por la reprográfica o por la copia privada de una grabación sonora o audiovisual, en la forma que determine el reglamento. Los programas de computadoras se regirán por lo pautado expresamente en las disposiciones especiales de esta ley sobre tales obras". 
reproducción (en relación de medio a fin): por ejemplo, una filmación o grabación videográfica de una escultura o de un cuadro para publicidad, proyección cinematográfica o televisiva" 129 .

La reproducción digital se realiza habitualmente en el lugar donde la obra está localizada, es decir el lugar de asiento del museo. Debido a que por lo general el soporte de la obra es un bien mueble ubicado dentro de un inmueble, parece razonable que la acción de reproducir esa obra se rija por el derecho del país del museo donde la copia digital fue obtenida.

Luego esa copia estará disponible en múltiples jurisdicciones, ya sea por el uso de las redes sociales donde es compartida, o porque se distribuye mediante correo electrónico, o porque está disponible en un sitio que permite sea accedida universalmente. A la fecha, "la extensión de la protección así como los medios procesales acordados al autor para la defensa de sus derechos se regirán exclusivamente por la legislación del país en que se reclama la protección" (Convenio de Berna, art. 5.2). Es el denominado "principio de territorialidad", que puede dar lugar a derechos más o menos extensos dependiendo de la legislación local. De aquí que múltiples legislaciones podrían ser aplicables para determinar la licitud de cada uno de los actos: reproducción, distribución, comunicación al público, etc.

El principio de territorialidad debería mitigarse para algunos usos en el entorno digital, por dar lugar a incertidumbres jurídicas, tanto para el artista como para los museos o usuarios ${ }^{130}$. Así, respecto de la digitalización y puesta a disposición de dichas reproducciones por parte del museo, debería aplicarse la ley de su ubicación, que coincide con el lugar de situación de la obra. Respecto de la validez de la inclusión de la fotografía de una pieza de la colección en un catálogo, también se debería regir por la ley situación del museo.

\section{G. LAS BUENAS PRÁCTICAS Y LOS CONTRATOS}

Una solución asequible para los museos frente a los problemas que hemos mencionado son las buenas prácticas de gestión y los contratos, con el fin de limitar los riesgos de la institución ${ }^{131}$. Esta es la situación en que se encuentran por aplicación del principio in dubio pro auctoris, ya que si el museo adquiere una colección, o si la recibe en donación o un legado y no se indica otra cosa, su actividad estará limitada a lo expresamente indicado por la ley. Dependiendo de la legislación

129 Rivero Hernández, "Reproducción de la obra plástica propiedad de museos y colecciones privadas", p. 1162.

130 Entre otras propuestas integrales que propenden a una revisión del principio de territorialidad, cfr. Metzger, Axel, "Applicable Law under the clip Principles: A Pragmatic Revaluation of Territoriality", en Jürgen Basedow, Toshiyuki Kono y Axel Metzger (editores), Intellectual Property in the Global Arena, Mohr Siebeck, Tübingen, 2010, pp. 157 y ss.

131 Association of Art Museums Directors, Guidelines for the Use of copyrighted Materials and Works of art by Art museums, 2017, disponible en https://aamd.org/standards-and-practices. Pantalony, La gestión de la propiedad intelectual en los museos, p. 27. Lima, Guía de Buenas Prácticas..., p. 35. 
nacional aplicable, el museo no la podrá reproducir ni comunicar al público ni incluirla en una obra audiovisual ${ }^{132}$. Además, los contratos de derecho de autor y en particular la cesión de derechos se interpretan restrictivamente; ello quiere decir que sólo los derechos que expresamente se hubieren cedido cambiarán de titularidad, permaneciendo el resto bajo el dominio del autor ${ }^{133}$.

Incluso, si las autoridades del museo no son previsoras, es probable que el museo adquiera cargas que no podrá cumplir. El mero hecho de recibir obras sin "beneficio de inventario" debería considerarse mínimamente negligencia. El directivo de un museo debe verificar qué derechos le está otorgando el autor a la institución y documentarlo debidamente, por ejemplo, mediante la inscripción del contrato ante la Dirección Nacional del Derecho de Autor. Otro tanto con las escrituras de donación, donde se deben especificar qué derechos se podrán ejercitar.

De aquí se podría deducir que las mejores prácticas recomendadas a los directivos de los museos será solicitar facultades muy amplias a los autores, herederos o propietarios de las obras respecto de cómo utilizar esas piezas, de modo de que la institución cuente con libertad de operación. Otro tanto se puede indicar en las políticas institucionales de los museos ${ }^{134}$. Sin embargo, también se corre el riesgo de irse al otro extremo del péndulo. Como indica Carpenter, interpretando la legislación estadounidense, los museos podrían ser una nueva especie de "predadores" respecto de los derechos morales del autor ${ }^{135}$.

Si las prácticas, las políticas institucionales y las cláusulas de estilo se tornan excesivamente restrictivas para los autores, se perdería el equilibrio buscado. Esto no se justificaría ni siquiera para que los museos puedan disponer de plenos derechos con el fin de obtener el mayor rédito de las colecciones y así asegurarse el financiamiento. Algunas prácticas son de por sí excesivas, como concluí al analizar el supuesto derecho de autor del museo sobre fotografías de obras en dominio público. Los museos, por tanto, deben limitar sus ambiciones incluso cuando cumplan un destacado papel social.

Una posibilidad es que las buenas prácticas sean consensuadas entre entidades representativas de artistas y asociaciones de museos, de modo que las partes cuenten con contratos modelos elaborados previamente en un marco paritario ${ }^{136}$.

132 Un estudio muy útil para elaborar las propias políticas y reglamentos en lo referente al uso de imágenes de los museos es el siguiente: Brown, Melissa A. y Crews, Kenneth D., "Art Image Copyright and Licensing: Compilation and Summary of Museum Policies", Columbia University. Disponible en http://www.kressfoundation.org/uploadedFiles/Sponsored_Research/ Research/Crews_appendix_1a.pdf, última visualización 16 de febrero de 2020. Allí se resumen las políticas de 50 museos.

133 Ruipérez de AzCÁrate, “El derecho de autor y sus límites: una encrucijada para los museos”, p. 98. Esta conclusión también se aplica en el ámbito norteamericano. Cfr. Malaro y DeAngelis, A Legal Primer on Managing Museum Collections, p. 182.

134 Cfr. Malaro y DeAngelis, A Legal Primer on Managing Museum Collections, p. 45 y ss.

135 Carpenter, “Drawing a Line in the Sand...", p. 489.

136 De modo general, a fin de poner luz sobre las cláusulas contractuales que afectan a los autores, cfr. Dietz, Adolf, "Protección de las personas creativas por el derecho de autor. Los cinco pilares del derecho de autor moderno de Europa Continental", 243 Revue Internationale du Droit D'auteur (2015), pp. 100-171, en 128. Este autor pone el ejemplo de las 
A modo de ejemplo, no es lo mismo que el museo solicite la cesión de todos los derechos patrimoniales respecto de cualquier tipo de explotación sobre la obra a que solo requiera los derechos necesarios para poder cumplir su misión central, como la posibilidad de incluir la obra en el catálogo, o reproducirla en la página virtual o bien tener la facultad de incluirla en un tour virtual ${ }^{137}$. Otra solución posible consiste en requerir todos los derechos de explotación de la obra, pero bajo la obligación de compartir con el artista los ingresos generados por cualquier explotación distinta de la mera exhibición, a modo de regalías.

Respecto de eventuales compromisos que las partes hayan asumido contractualmente, además de considerarse la validez sustancial, deberá verificarse la validez formal y probatoria del contrato. En la mayoría de los países los contratos deben registrarse para ser oponibles a terceros ${ }^{138}$. La situación es inusual, primero por la informalidad que rige la actividad museística en los países de la región. Luego, porque aun cuando se formalicen adecuadamente los vínculos contractuales, los instrumentos no suelen registrarse y por tanto dejan de ser oponibles a terceros, como los sucesivos adquirentes, herederos o terceros que utilicen la obra sin autorización.

\section{CONCLUSIÓN}

Los museos han ampliado su ámbito de actividad, lo cual conlleva potenciales y reales conflictos de interés con los titulares de las obras, sus herederos, el público y otros interesados, como los creadores de obras derivadas.

Ante la falta de armonía, resulta necesaria una mayor previsión, en algunos casos previendo reglas jurídicas más precisas en el ámbito interno. También se debe recurrir a buenas prácticas y políticas institucionales que permitan una mejor gestión del patrimonio artístico administrado, principalmente mediante contratos y reglamentos. Sin perjuicio de esta diligencia, se advierten situaciones que requieren una solución legislativa.

También se advierte una necesidad de armonización internacional, mediante reglas de derecho internacional privado que regulen los efectos extraterritoriales de las limitaciones y excepciones, como, por ejemplo, la aplicación del principio lex originis para las digitalizaciones del acervo.

paritarias entre traductores y editores a fin de contar con modelos de contratos respetuosos de los intereses de las partes.

137 Una cláusula por incluir en el contrato de adquisición de la obra, en el ámbito anglosajón, es la habilitación anticipada del artista para todo uso que pueda considerarse parte del fair use. Cfr. Association of Art Museums Directors, Guidelines for the Use of copyrighted Materials and Works of art by Art museums, p. 10. También Malaro y DeAngelis, A Legal Primer on Managing Museum Collections, p. 185.

138 Sommaruga, Nicolás, "El registro de contratos ante la Dirección Nacional del Derecho de Autor de la República Argentina", en Anuario de la Revista Iberoamericana de la Propiedad Intelectual, Universidad Austral, tomo 5, Buenos Aires, 2017, p. 89 y ss. 
Anguita Villanueva, Luis Antonio, "La extraña pareja: la difícil relación jurídica entre la normativa de propiedad intelectual y la de patrimonio cultural en los museos", en Museos y propiedad intelectual, Carlos Rogel y Andrés Domínguez (directores), Reus, Madrid, 2012.

Antequera Parilli, Ricardo, Estudios de Derecho de Autor y Derechos Afines, AIsGeMarcial Pons, Madrid, 2007.

Association of Art Museums Directors, Guidelines for the Use of copyrighted Materials and Works of art by Art museums, 2017, disponible en https://aamd. org/standards-and-practices.

Benhamou, Yaniv, "Limitaciones y excepciones en materia de derecho de autor para los museos: análisis tipológico", Documento WIPO SCCR/38/6.

Brown, Melissa A. y Crews, Kenneth D., "Art Image Copyright and Licensing: Compilation and Summary of Museum Policies", Columbia University. Disponible en http://www.kressfoundation.org/uploadedFiles/Sponsored_Research/ Research/Crews_appendix_1a.pdf.

Busaniche, Beatriz, Propiedad intelectual y derechos humanos. Hacia un sistema de derecho de autor que promueva los bienes culturales, Tren en Movimiento, Temperley, 2016.

Bustamante Alsina, Jorge, "El contrato de exhibición de obra de arte es atípico e innominado. Responsabilidad del expositor", Revista Jurídica La Ley, Buenos Aires, 1997-F-649.

Canaris, Claus-Wilhelm, El sistema en la jurisprudencia, Fundación Cultural del Notariado, Madrid, 1998, trad. de la 2a ed. alemana de Juan Antonio García Amado (Systemdenken und Systembegriff in den Jurisprudenz: entwickelt am Beispiel des deutschen Privatrechts. 2. überarbeitete Auflage. Berlin, 1983).

Carpenter, Megan M., "Drawing a Line in the Sand: Copyright Law and New Museums", 13 Vand. J. Ent. \& Tech. L. 463, 2011.

Casas Vallès, Ramón "Los casos Barceló y Boadella”, Doctrina IIDA, 2008.

Chapman, Audrey R. "Approaching intellectual property as a human right: obligations related to Article 15 (1) (c)", Unesco Copyright Bulletin, volume Xxxv n. ${ }^{\circ} 3$, July-September 2001, pp. 4-36.

Cianciardo, Juan "Principios y reglas: una aproximación desde los criterios de distinción”, Boletín Mexicano de Derecho Comparado, nueva serie, año xxxvI, núm. 108, Ciudad de México, septiembre-diciembre de 2003.

Córdoba Marentes, Juan Fernando, El derecho de autor y sus límites, Editorial Temis, Bogotá, 2015.

Cornides, Jakob, "Human Rights and Intellectual Property - Conflict or Convergence?", Journal of World Intellectual Property, 2004.

Cottier, T., Bürgi, E. y Pauwelyn, J. (eds.), Human Rights in International Trade, Oxford University Press, Nueva York, 2005. 
Crews, Kenneth D. y Brown, Melissa A., "Control of museum art images: the reach and limits of copyright and licensing", en The Structure of Intellectual Property Law. Can One Size Fit All?, Annette Kur y Vytautas Mizaras (ed.), Edward Elgar, Cheltenham, 2011.

Crews, Kenneth D., "Museum Policies and Art Images: Conflicting Objectives and Copyright Overreaching", Fordham Intell. Prop. Media \& Ent. L.J., vol. 22:795.

De la Parra Trujillo, Eduardo, Derechos humanos y derechos de autor. Restricciones al derecho de explotación, Segunda Edición, Instituto de Investigaciones Jurídicas, Serie Estudios Jurídicos n. ${ }^{\circ}$ 721, unAm, CDMX, 2015.

Derclaye, Estelle, "Intellectual Property Rights and Human Rights: Coinciding and Cooperating", en Torremans, Paul L. C. (ed.), Intellectual Property and Human Rights, pp. 133-160.

Dessemontet, Francois, "Copyright and Human Rights", en Intellectual Property and Information Law, Jan KaBeL (ed.), Kluwer, The Netherlands, 1998.

Dietz, Adolf, "Protección de las personas creativas por el derecho de autor. Los cinco pilares del derecho de autor moderno de Europa Continental", 243 Revue Internationale du Droit D'auteur (2015), pp. 100-171.

Elizalde Perdiz, Rosalba, comentario al artículo 21 lfda, en Ley Federal de Derecho de Autor, comentada por la Asociación Mexicana para la Protección de la Propiedad Intelectual (MPPI), Miguel Ángel OrTiz BAHENA (coordinador), Editorial Porrúa, CDMx, 2017.

EMERY, Miguel Ángel, "Los derechos intelectuales de los artistas plásticos. La originalidad en las obras artísticas", Revista El Derecho, t. 243, p. 645.

Emery, Miguel Ángel, Propiedad Intelectual, 2a edición actualizada y ampliada, Astrea, Buenos Aires, 2019.

Fischman Afori, Orit, "Human Rights and Copyright: The Introduction of Natural Law Considerations into American Copyright Law", 14 Fordham Intell. Prop. Media \& Ent. L. J. 497 (2004).

Garvin, Kaitlyn M. "Reclaiming Our Domain: Digitization of Museum Collections and Copyright Overreach", IDEA - The Law Review of the Franklin Pierce Center for Intellectual Property, volume 59 - number 2.

Geiger, Christophe y Izyumenko, Elena, "Freedom of expression as an external limitation to copyright law in the EU: The Advocate General of the CJEU shows the way", Center for International Intellectual Property Studies, Research Paper n. ${ }^{\circ} 2018-12$.

Gervais, Daniel, "The Internet Taxi: Collective Management of Copyright and the Making Available Right, after the Pentalogy", en The Copyright Pentalogy, Michael Geist (dir.), University of Ottawa Press, 2013, pp. 373-401.

Goldstein, Paul y Hugenholtz, Bernt, International Copyright: Principles, Law and Practice, Oxford University Press, Third Edition, Nueva York, 2013.

Grosheide, Willem, Intellectual Property and Human Rights. A Paradox, CierEdward Elgar Publishing Limited, Cheltenham, 2010. 
Grosseries, Axel, Marciano, Alain y Strowel, Alain (editores), Intellectual Property and Theories of Justice, Ed. Palgrave Macmillan, Londres, 2010.

Guzmán, Diego, Derecho del Arte, Universidad Externado de Colombia, Bogotá, 2018.

Iglesias Rebollo, César, "Inclusión de obras plásticas en otras obras", en Museos y propiedad intelectual, Carlos Rogel y Andrés Domínguez (directores), Reus, Madrid, 2012.

LeE, Brian A., "Making Sense of 'Moral Rights' in Intellectual Property" (February 15, 2012), Temple Law Review, vol. 84, Brooklyn Law School, Legal Studies Paper n. ${ }^{\circ}$ 261, 2011.

Lima, María Clara, Guía de Buenas Prácticas - Administración de la propiedad intelectual en museos y archivos de la Argentina, Edulp, La Plata, 2011.

Lipszyc, Delia y colaboradores, Régimen legal de la propiedad intelectual, Hammurabi, Buenos Aires, 2019.

Lipszyc, Delia, Derecho de autor y derechos conexos, Unesco-Cerlalc-Zavalía, Buenos Aires, 2006.

Lorenzetti, Ricardo L., "El juez y las sentencias difíciles - Colisión de derechos, principios y valores", Revista Jurídica La Ley, Buenos Aires 1998-A, 1039-1054.

Malaro, Marie C. y DeAngelis, Ildiko Pogáni, A Legal Primer on Managing Museum Collections, Third Edition, Smitshonian Books, Washington, 2012.

Malovic, Nedim, "Swedish Supreme Court favours copyright protection over freedom of information and of the press", IPKat, 22 de marzo de 2020, disponible en http://ipkitten.blogspot.com/2020/03/swedish-supreme-court-favourscopyright.html.

Marín López, Juan José, El conflicto entre el derecho moral del autor plástico y el derecho de propiedad sobre la obra, Aranzadi, Madrid, 2006.

Marzetti, Maximiliano, Propuestas para ampliar el acceso a los Bienes Públicos en Argentina, Clacso, Buenos Aires, 2013.

Massot, Juan Miguel, "Análisis económico de los derechos de propiedad intelectual en semillas", en Innovación en propiedad intelectual en mejoramiento vegetal y biotecnología agrícola, Miguel Rapela y Gustavo Schötz (coord.), HeliastaUniversidad Austral, Buenos Aires, 2006.

Merryman, John Henry, Elsen, Albert E. y Urice, Stephen K., Law, Ethics and the Visual Arts, fifth edition, Kluwer Law International, The Netherlands, 2007.

Metzger, Axel, "Applicable Law under the Clip Principles: A Pragmatic Revaluation of Territoriality”, en Jürgen BAsedow, Toshiyuki Kono y Axel MetzGer (editores), Intellectual Property in the Global Arena, Mohr Siebeck, Tübingen, 2010.

Navas Navarro, Susana, "Integridad y transformación de obras que se encuentran en el dominio público. En tono a su apropiación en exclusiva por terceros”, en Carlos Rogel (dir.), Los derechos morales de los creadores, Reus, Madrid, 2019. 
Nordemann, Jan Bernd y LeidL, Laura, "German Bgh: The destruction of the work does not infringe the moral rights of the author", Kluwer Copyright Blog, 19 de agosto de 2019, disponible en http://copyrightblog.kluweriplaw. com/2019/08/19/german-bgh-the-destruction-of-the-work-does-not-infringethe-moral-rights-of-the-author/.

Olmedo Velázquez, Efraín, "Limitantes en la adquisición de obras de arte en México", Revista Mexicana del Derecho de Autor, Indautor, n. ${ }^{\circ}$ 3, México, segundo semestre 2013, Issn: 2007-5677.

Ortega Doménech, Jorge, Obra plástica y derechos de autor, Reus, Madrid, 2000.

PANTAlONY, Rina Elster, La gestión de la propiedad intelectual en los museos, OMPI, Ginebra, 2013.

Parets Gómez, Jesús, Originalidad, creatividad y registro del derecho de autor, Ed. Sista, Ciudad de México, 2018.

Petri, Grischka, “The Public Domain vs the Museum: The Limits of Copyright and Reproductions of Twodimensional Works of Art", Journal of Conservation and Museum Studies, 12(1).

Prieto de Pedro, Jesús "Cuando los tribunales definen el arte o una escultura que no era un utensilio de cocina: el caso Brancusi", Derecho del Arte, Anuario Iberoamericano 2016, Civitas-Thomson Reuters, Madrid, 2016.

Ricketson, Sam y Ginsburg, Jane, International Copyright and Neighbouring Rights. The Berne Convention and Beyond, Oxford University Press, Second Edition, vol. I, Nueva York, 2010.

Ricketson, Sam, "Estudio sobre las limitaciones y excepciones relativas al derecho de autor y a los derechos conexos en el entorno digital", documento wIPO sCCR/9/7, 5 de abril de 2003.

Rivero Hernández, Francisco, "Reproducción de la obra plástica propiedad de museos y colecciones privadas", Revista Critica de Derecho Inmobiliario, n. ${ }^{\circ} 622$, mayo-junio 1994, pp. 1149-1198.

Rogel Vide, Carlos, "Exposición pública de obras plásticas", en Museos y propiedad intelectual, Carlos Rogel y Andrés Domínguez (dirs.), Reus, Madrid, 2012.

Romero, Carolina, "Los conceptos corpus mysticum y corpus mechanicum. Su aplicación hoy en día en el contexto análogo y digital", Revista Iberoamericana de Derecho de Autor, Unesco-Cerlalc, Año viI - n. ${ }^{\circ} 14$ - enero-diciembre, 2014.

RosatTi, Eleonora, "Milan court partly sides with Banksy in interim proceedings for trade mark and copyright infringement", IPKat, 2 de marzo de 2019, http:// ipkitten.blogspot.com/2019/03/milan-court-sides-with-banksy-in.html.

Ruipérez de AzCÁrATe, Clara, "El derecho de autor y sus límites: una encrucijada para los museos", en Museos y propiedad intelectual, Carlos Rogel y Andrés Domínguez (directores), Reus, Madrid, 2012.

SÁnchez Aristi, Rafael, "La propiedad trenzada. El juego de lo material y lo inmaterial en las obras de arte", en Derecho del Arte, Anuario Iberoamericano 2015, Fundación Prof. Uría, Civitas, Madrid, 2015. 
Sснӧтz, Gustavo (coord.), Patentes y medicinas esenciales, Heliasta-Universidad Austral, Buenos Aires, 2013.

SCHUSter, Santiago, Las excepciones al derecho de autor como normas permisivas. Una revisión critica del derecho de usuario en el sistema normativo de derecho de autor, Universidad de Chile, tesis para optar al Grado de Doctor en Derecho, manuscrito inédito, noviembre de 2019.

Serna, Pedro y Toller, Fernando, La interpretación constitucional de los derechos fundamentales. Una alternativa a los conflictos de derechos, La Ley, Buenos Aires, 2000.

Solórzano Solórzano, Raúl, "En torno al derecho moral del autor a la integridad de su obra: reflexiones a propósito del daño efectuado a los murales en el Centro de Lima", Revista de la Facultad de Derecho de la PUCP, Lima, n. ${ }^{\circ}$ 74, 2015.

Sommaruga, Nicolás, "El registro de contratos ante la Dirección Nacional del Derecho de Autor de la República Argentina", en Anuario de la Revista Iberoamericana de la Propiedad Intelectual, Universidad Austral, tomo 5, Buenos Aires, 2017.

The Register of Copyrights, Waiver of Moral Rights in Visual Artworks, Final Report, Washington, 1996.

Tobón Franco, Natalia y Varela Pezzano, Eduardo "Dos problemas jurídicos alrededor de las fotografías: la originalidad y el derecho a la intimidad", Anuario de la Revista Iberoamericana de la Propiedad Intelectual, tomo 3, Buenos Aires, 2015.

Товón Franco, Natalia, "Limitaciones al derecho moral de obras arquitectónicas", Anuario de la Revista Iberoamericana de la Propiedad Intelectual, tomo 5 , Buenos Aires, 2016.

Toller, Fernando, "Resolución de los conflictos entre derechos fundamentales, una metodología de interpretación constitucional alternativa a la jerarquización y el balancing test", en Interpretación constitucional, Eduardo Ferrer Mac-Gregor (coord.), Editorial Porrúa, México, 2005.

Torremans, Paul L. C. (ed.), Intellectual Property and Human Rights, 2nd Edition, Kluwer Law International, The Netherlands, 2008.

Treiger-Bar-Am, Leslie Kim, "The Moral Right of Integrity: A Freedom of Expression", en New Directions in Copyright, vol. 2, Fiona Macmillan (ed.), Edward Elgar, Londres, 2006.

van Deursen, Stijn y Snijders, Thom, "The Court of Justice at the Crossroads: Clarifying the Role for Fundamental Rights in the EU Copyright Framework, IIC (2018) 49:1080-1098.

Vicente Domínguez, Elena, "Derechos de autor en la venta y el alquiler de la obra plástica”, en Museos y propiedad intelectual, Carlos Rogel y Andrés DoMÍNGUEZ (directores), Reus, Madrid, 2012.

wIPO Documento CE/MPC/III/3, publicado en Copyright, Monthly Review of the World Intellectual Property Organization (wIPO) n. ${ }^{\circ} 9$ September 1990. 
WIPO Documento SCCR 33/4, 1. de noviembre de 2016, disponible en https:// www.wipo.int/edocs/mdocs/copyright/es/sccr_33/sccr_33_4.pdf.

WIPO SCCR/38/6, "Limitaciones y excepciones en materia de derecho de autor para los museos: análisis tipológico", 29 de marzo de 2019, disponible en https:// www.wipo.int/edocs/mdocs/copyright/es/sccr_38/sccr_38_6.pdf.

Yu, Peter K., "Ten Common Questions About Intellectual Property Rights and Human Rights", Georgia State University Law Review, vol. 23-4. 